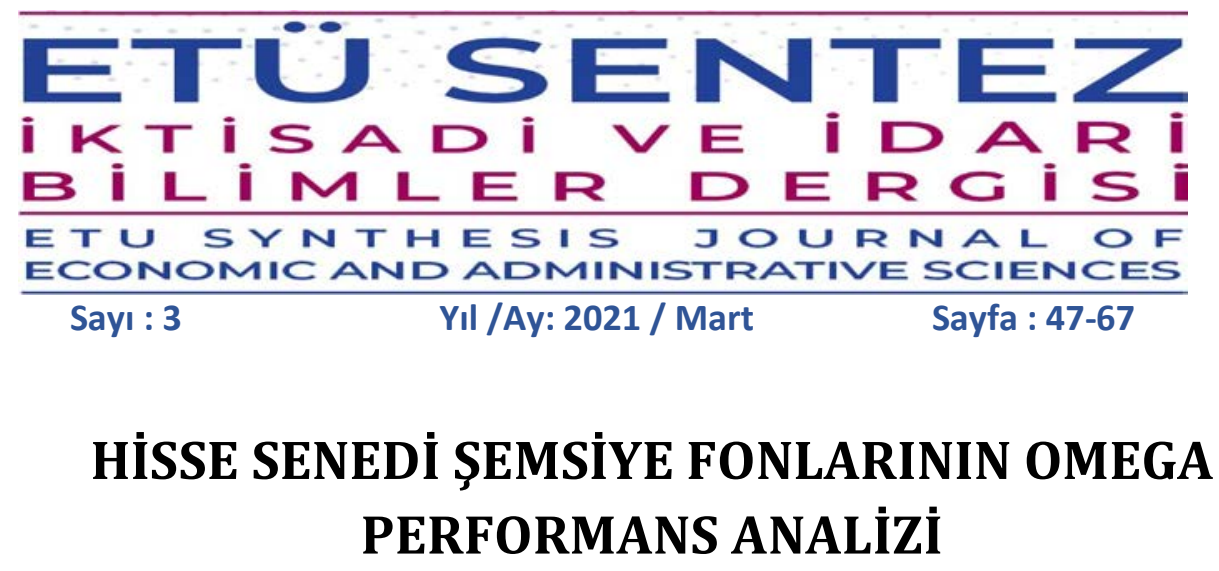

Zehra Tanyeli Aksoy

Düzce Üniversitesi, Sosyal Bilimler

Enstitüsü,

e-mail: zehratanyelia@gmail.com

ORCID: 0000-0001-8874-8176

\section{Nevin Özer}

Dr. Öğr. Üyesi, Düzce Üniversitesi, İşletme Fakültesi, İşletme Bölümü, e-mail: nevinozer@duzce,edu.tr, ORCID: 0000-0002-1736-4199

İstemi Çömlekçi

Doç. Dr. Düzce Üniversitesi, İşletme Fakültesi, Uluslararası Ticaret ve Finansman Bölümü, e-mail: istemicomlekci@duzce.edu.tr ORCID: 0000-0001-8922-071X

DOI : 10.47358/sentez.2020.14

Makale Türü : Araştırma

Gönderim Tarihi: 14.01.2021

Düzeltme Tarihi: 22.02.2021

Kabul Tarihi: 01.03.2021

Bu makaleye atıfta bulunmak için: Aksoy, Z. T. Özer, N. ve Çömlekçi, İ. (2021). Hisse Senedi Şemsiye Fonlarının Omega Performans Analizi. ETÜ Sentez İktisadi ve İdari Bilimler Dergisi. Sayı: 3, 47-67.

\section{$\checkmark$ iThenticate}

Öz: $\mathrm{Bu}$ çalışmanın amacı hisse senedi şemsiye fonlarının performanısını Omega performans ölçümü ile incelemektir. Omega performans ölçümü, eşik değer adı verilen yatırımcıların belirli bir risk sınırını ya da bekledikleri getiri oranı üzerinden performans sıralaması yapmaktadır. Çalışmada eşik değer olarak \%1'den \%10'a kadar beklenen getiri oranı değerleri belirlenmiştir. 2016-2020 yılları arasında Türkiye Elektronik Fon Dağıtım Platformu (TEFAS)'da işlem gören 48 adet hisse senedi şemsiye fonu getirileri kullanılmıştır. Analiz sonucunda farklı eşik değerlerinde 1'den 10'a kadar sıralamalar yapılmıştır. Beklenen getiri oranı artırıldığı zaman hisse senedi fon sıralamasında değişiklik olduğu tespit edilmiştir.

Anahtar Kelimeler:Hisse Senedi Yatırım Fonu, Omega Oranı, Performans Ölçütü

Jel Kodları:G11, G17, G23. 


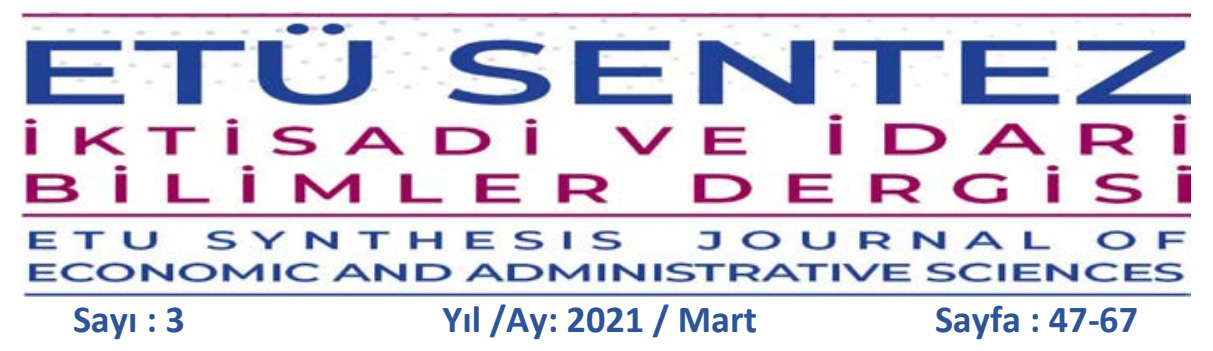

\section{OMEGA PERFORMANCE ANALYSIS OF STOK UMBRELLA FUNDS}

Zehra Tanyeli Aksoy

Duzce University, Graduate School of Social Sciences,

e-mail: zehratanyelia@gmail.com

ORCID: 0000-0001-8874-8176

\section{Nevin Ozer}

Asis. Prof., Duzce University, Faculty of Business, Departmant of Business, e-mail: nevinozer@duzce,edu.tr, ORCID: 0000-0002-1736-4199

İstemi Çomlekci

Assoc. Prof., Duzce University, Faculty of Business, Departmant of International Trade and Finance, e-mail: istemicomlekci@duzce.edu.tr ORCID: 0000-0001-8922-071X

DOI : $10.47358 /$ sentez.2020.14

Article Type : Research

Application Date: 01.14.2021

Revision Date: 02.22.2021

Admission Date: 03.01.2021

To cite this article:

Aksoy, Z. T. Ozer, N. and Comlekci, I. (2021). Omega Performance Analysis of Stok Umbrella Funds. ETU Synthesis Journal of Economic and Administrative Sciences. Issue: 3, 47-67.

This article was checked by $\checkmark$ iThenticate
Abstract: The aim of this study is to examine the performance of the stock umbrella funds with the Omega performance measurement. Omega performance measurement ranks the performance of investors based on a certain risk limit or the expected return rate, called threshold value. In the study, expected return rate values from $1 \%$ to $10 \%$ were determined as the threshold value. Between the years 2016-2020 Turkey Electronic Funds Distribution Platform (TEFAS) also traded 48 stock umbrella funds' return data are used. As a result of the analysis, ranks from 1 to 10 were made in different threshold values. When the expected return rate was increased, it was determined that there was a change in the stock fund ranking.

Keywords :Equity Mutual Fund, Omega Ratio, Performance Measure

Jel Classification :G11, G17, G23. 


\section{Gíkiş}

Yatırımcılar finansal piyasalarda yatırım yaparken çeşitli faktörleri incelemeleri, analiz etmeleri ve yorumlamaları gerekmektedir. Ancak yatırımcılar hem zaman hem de bilgi açısından bu konularda yeterli olmayabilir. Bu sebeple, bireysel yatırımcıların karşısına profesyoneller tarafından yönetilen yatırım fonları gibi alternatifler sunulmuştur. Yatırım fonlarının tarihi 1800'lü yıllara kadar dayanmaktadır. Ancak modern anlamda yatırım fonları 1900'lü yıllarda popüler olmuştur. Amerika'da 1920'ler, Avrupa'da ise 1930'lar yatırım fonlarının yatırımcıların ilgisini çektiği yıllar olmuştur ve ilk menkul kıymet yatırım fonu 1924 yılında Amerika Birleşik Devletleri'nde kurulmuştur. (Kahraman, 2006).

Gelişmiş ülkelerde uzun yıllar yatırımcılar tarafından kullanılan yatırım fonlarının Türkiye sermaye piyasasına girişi 1980'li yıllardır. Bu yıldan sonra yatırım fonları hem sayısal olarak artmış, hem de yatırımcıların ilgisini çekmeyi başarmıştır. 17 yatırım fonuyla başlayan piyasa, 2020 yılına gelindiğinde 515 yatırım fonu bulunmaktadır. Grafik 1'e bakıldığında Türkiye'de 2000'li yıllarda yatırım fonlarının bazı yıllarda küçük inişler yaşasa da genellikle artış trendi içinde olduğu görülmektedir.

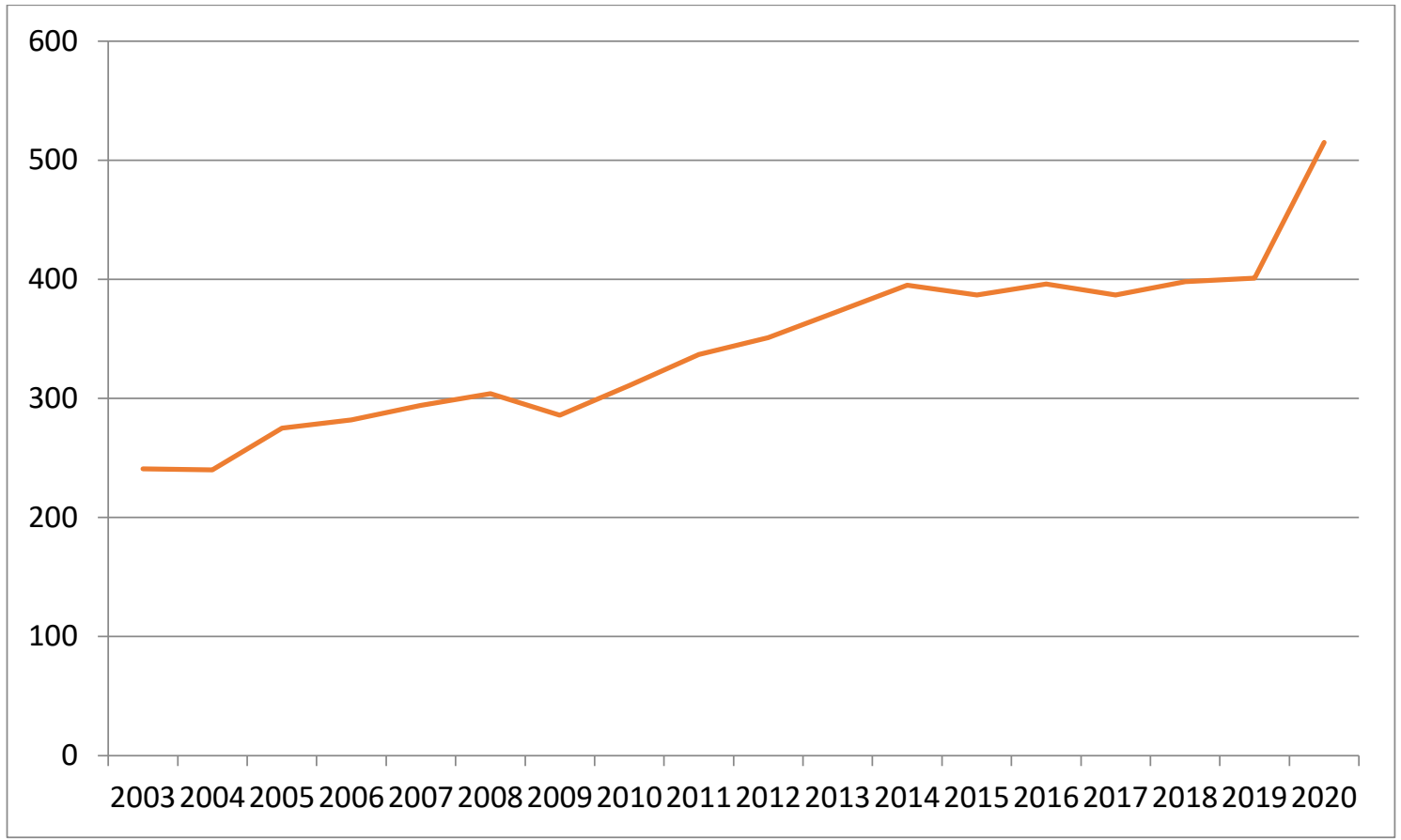

Grafik 1: Türkiye'de Yatırım Fonlarının Sayısı

(Kaynak: www.spk.gov.tr)

Dünyadaki duruma bakıldığında, yatırım fonlarına ilginin her geçen gün arttığı görülmektedir. Özellikle gelişmiş ülkelerde yatırım fonlarının sermaye piyasalarında önemli bir 
yeri olduğu Grafik 2'de görülmektedir. Türkiye gibi gelişmekte olan ülkelerde ise piyasalar geç tanışmış olmasına rağmen devamlı büyüyen yapıya sahiptir. Ancak Türkiye'nin durumu Grafik 2'de incelendiğinde, diğer ülkelere göre arzu edilen seviyenin altında kaldığı söylenebilir. Ayrıca Türkiye'nin, Brezilya, Güney Afrika, Hindistan gibi gelișmekte olan ülkelerinde gerisinde olduğu ve yatırım fon sayısının oldukça düşük sayıda kaldığı görülmektedir.

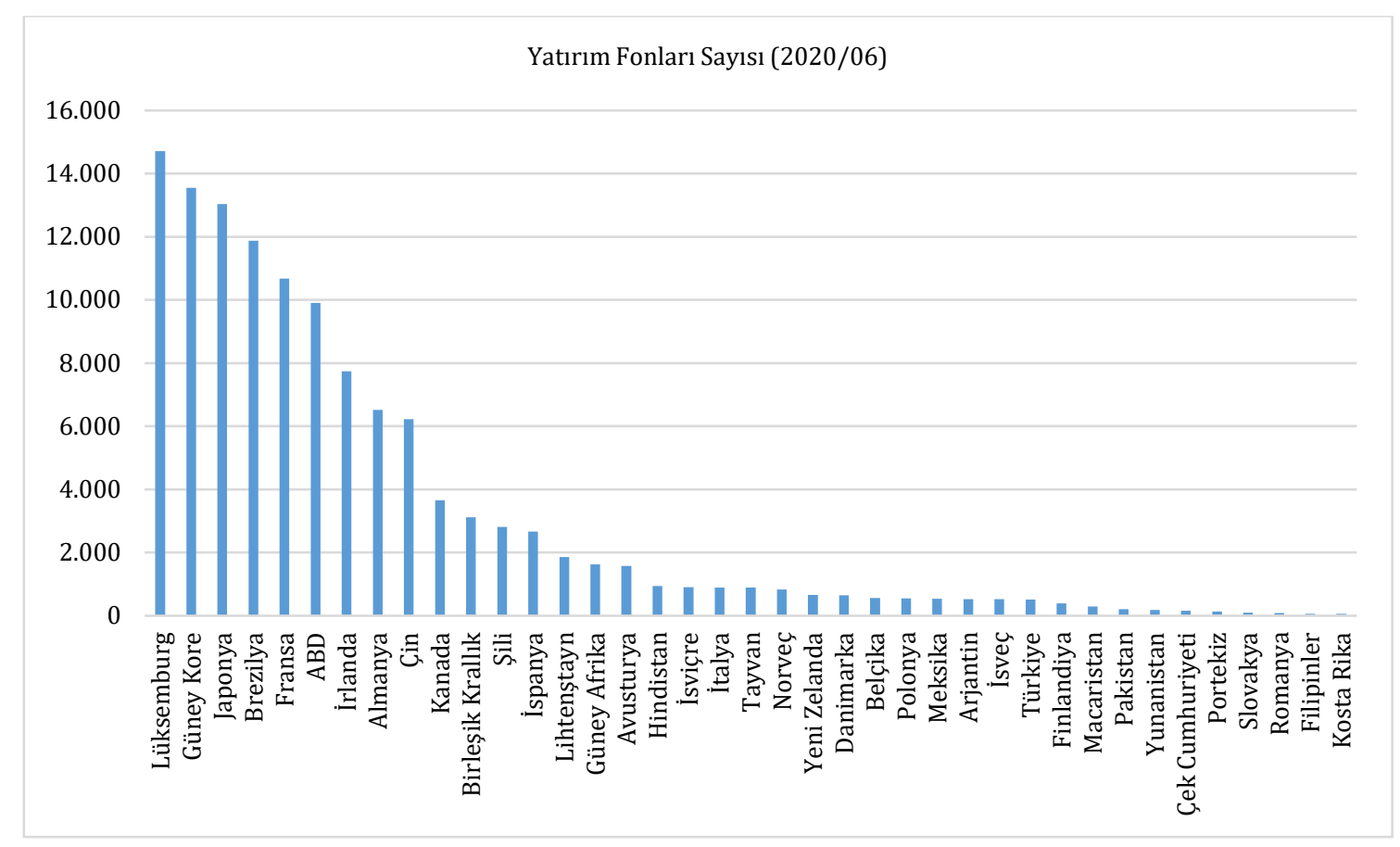

Grafik 2: Dünyadaki yatırım fonlarının sayısı

(Kaynak: www.spk.gov.tr)

Günümüzde yatırım fonları, sayı olarak artmasının yanında yatırımcıların taleplerine göre de şekillenmekte ve çeşitliliği artmaktadır. Farklı yatırım araçlarından oluşan çeşitlendirilmiş portföyler ya da belirli yatırım aracına yoğunlaşmış odaklanmış portföylerden oluşan yatırım fonları ortaya çıkmıștır. Türkiye'deki yatırım fon çeşitliliğinin işlem hacmi açısından \% olarak dağılımı Grafik 3'de görülmektedir. 


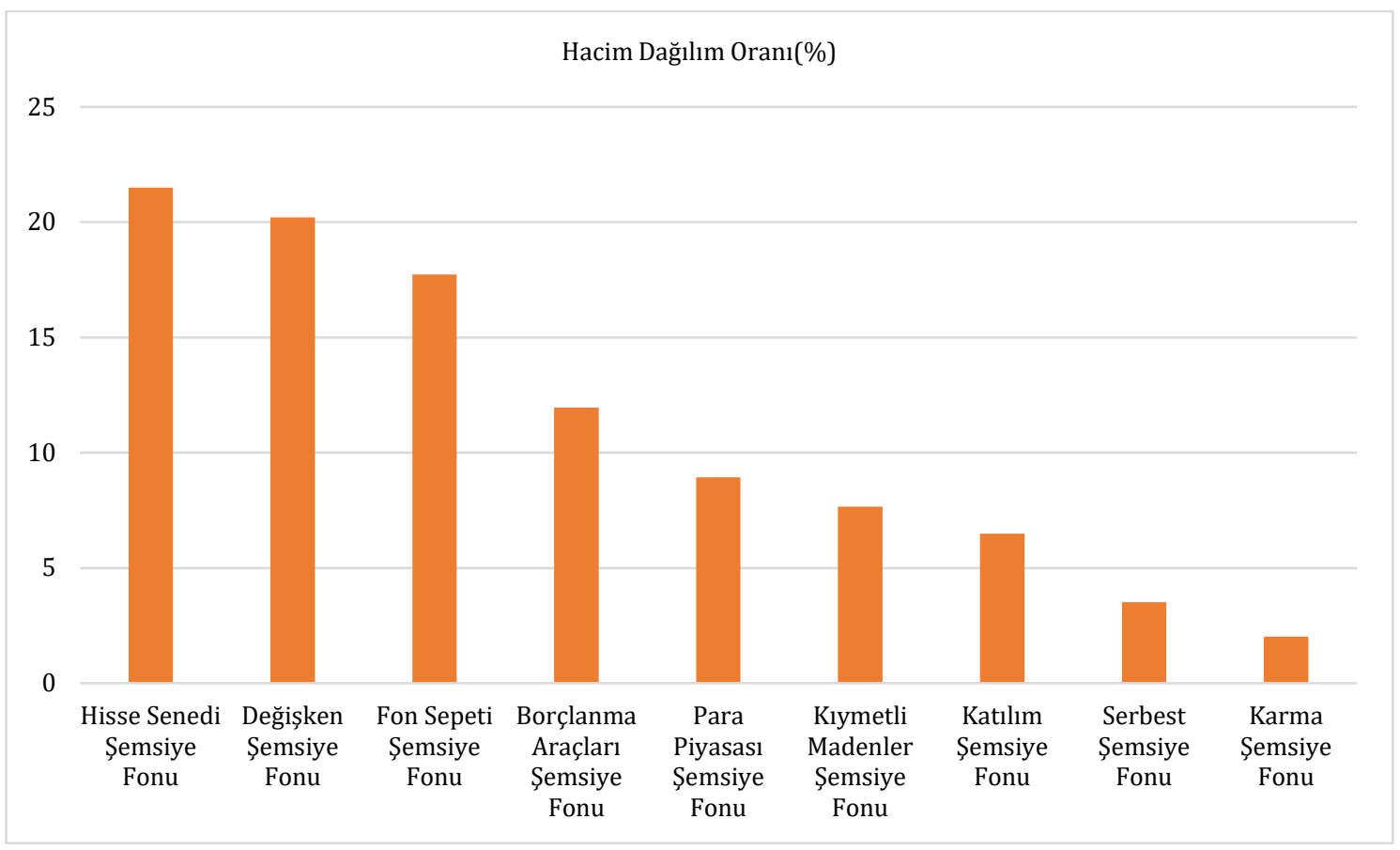

Grafik 3: 2020 Yılı Türkiye'de Yatırım Fonları Hacimsel Dağılımı

(Kaynak: www.tefas.gov.tr)

Grafik 3 incelendiğinde işlem hacmi açısından hisse senedi şemsiye fonlarının diğer fonlardan daha fazla işlem hacmine sahip olduğu görülmektedir. Bu nedenle çalışmada, en çok işlem hacmine sahip olan hisse senedi şemsiye fonları seçilmiştir.

Yatırımcılar açısından önemli konulardan birisi de yatırım fonlarının göstermiş olduğu finansal performanstır. Finansal performans ölçümü, portföy idaresinde, yatırım planlaması ve karar alma sürecinde önemli bir rol oynamaktadır. Bireyler yatırım yaptıkları fonları nasıl en iyi şekilde değerlendirebileceğine dönük sorulara cevap aramaktadır. Yatırımcıların aradıkları cevaplara, finansal performans değerlendirmesi ile ulaşabilme firsatları bulunmaktadır. Yatırım kararlarının alınmasında fonların getirileri ve taşıdıkları risk oranı yatırımcılar için çok önemlidir. Yatırımcılar birikimlerini değerlendirecekleri fonları seçerken söz konusu fonların yıllar içerisinde göstermiş olduğu performansını incelemektedir. Karar verme sürecinde kapsamlı bir şekilde performans ölçümünün gerçekleştirilmesi ve birden fazla kriterin analize dâhil edilmesi sonucunda başarı sıralamasının oluşturulması büyük bir önem arz etmektedir (Uygurtürk ve Bal, 2020). Dumanoğlu ve Ergül (2010), mali performans ölçülmesinde farklı hesaplama tekniklerinin kullanılmasının ve yorumlanmasının önemine dikkatleri çekmiştir. Kahraman (2006), 2000-2004 yılları arasında Türkiye'de yapmış olduğu çalışmasında, menkul kıymet yatırım fonları performansının farklı çevrelerin merak ettiği bir konu olduğunu vurgulamıștır.

Performans analizleri ile ilgili genel olarak literatür incelendiğinde Sharpe oranı, Treynor oranı, Jensen oranları gibi oranların kullanıldığı görülmüştür. Bu çalışmada diğer performans ölçütlerine göre çarpıklık ve basıklık gibi bir dağılımın daha yüksek anlarını ve portföy üzerinde 
yüksek etkiye sahip olabilecek düşük olasılıklı olayları dikkate alması nedeniyle Omega oranı ile getiri analizi yapılmıştır. 2016-2020 yılları arasında Türkiye Elektronik Fon Dağıtım Platformu (TEFAS)'da işlem gören 48 adet hisse senedi şemsiye fonlarının günlük fiyat verileri kullanılarak getirileri hesaplanmış ve performansları incelenmiştir.

\section{LİTERATÜR}

Yatırım fonlarının performansının ölçülmesi 1960'lı yıllarda gelişmiş ülkelerde incelenmeye başlamıştır. Friend vd (1962), Treynor (1965), Sharpe (1966), ve Jensen (1968), bu alanda yapılan ilk çalışmalardır. Treynor (1965); Treynor Oranı, Sharpe (1966); Sharpe Oranı ve Jensen (1968), Jensen Oranı olarak literatüre girmiş ve yatırım fonlarının performanslarının değerlendirilmesinde birçok çalışmada kullanılmıştır. Keating ve Shadwick (2002a), çalışmasında performans ölçümünde getiri dağılımının ortalama ve varyans varsayımında hatalara sebep olmasından dolayı Omega oranını ortaya koymuşlardır. Omega oranı hesaplamaları, yatırımcıya kabul edilen minimum getiriyi seçme özgürlüğü verir; daha sonra riski yatırım ile modeller. Omega oranı, varlık getirilerinin herhangi bir dağılımı için kullanılabilir (Kapsos vd., 2014). Normal dağılım varsayımına bağlı olmadığı için normal dağılım olmayan getirileri olan finansal varlıkların performans ölçümlerinde önerilmektedir. (Steinki ve Mohammad, 2015). Literatürde fon performanslarının ölçümüyle ilgili seçilmiş çalışmalar aşağıda sunulmuştur.

Hodges vd. (2003), S\&P' de işlem gören 500 hisse senedinin ortalama getiri ve piyasa kovaryansları ile beta ve Treynor oranlarını analiz ederek başarı sıralamasını incelemişlerdir. Analiz sonucunda portföylerin göreceli sıralaması, amaçlanan elde tutma süresine bağlı olduğunu belirtmişlerdir. Uzun elde tutma süreleri için adi hisse senedi portföyü, küçük hisse senetlerinin ve tahvillerin portföyünden daha iyi performans gösterdiğini tespit etmişlerdir. Ayrıca beta değerleri ve Treynor oranlarının, elde tutma süresi ve yatırım görüşüyle eşleşiyorsa anlamlı olduğunu, bu nedenle de bu parametrelerin dikkatli kullanılması gerekliliğini vurgulamışlardır.

Hübner (2005), 1994-2003 yılları arasında S\&P' de işlem gören 50 portföyden oluşan iki set oluşturarak Treynor oranı ile performans sıralaması yapmıştır. Analiz sonucunda bu ölçümün kesin ve istikrarlı olduğunu yani portföy yöneticisi sistematik riske maruz kalsa dahi Treynor oranı ile sıralamanın varlık fiyatlama modelindeki değișikliklere karşı sağlam olduğu sonucuna varmıştır.

Farinelli vd. (2008), 02/04/1984 ve 03/10/2005 tarihleri arasında S\&P, D\&J, NASDAQ, FTSE ve NIKKEI endeksleri üzerinde yapmış olduğu çalışmasında, on bir performans oranından oluşan bir araç setine en iyi performans oranları üzerinde bir sağlamlık testi yapmıştır. Çalışma sonucunda, en iyi oran olma konusundaki sağlamlık testi sonucu, Sharpe oranı zayıflığını göstermiştir ancak asimetrik oranlardan, yani Sortino-Satchell, Genelleştirilmiş Rachev ve Farinelli-Tibiletti oranlarından daha iyi performans gösterme kabiliyetini tespit etmişlerdir.

Chaudhry ve Johnson (2008), 1980- 2006 yılları arasında, Avustralya'da ASX300 endeksinde işlem gören A ve B tipi fonların performans ölçümleri ve yönetici performanslarını 
sıralamak için yaptığı analizde; Sortino oranının göreceli sapmasının Sharpe oranından biraz daha düşük olduğunu tespit etmişlerdir. Sortino oranının daha iyi bir performans ölçüsü olduğunu sonucuna ulaşmıştır.

Samırkaş ve Düzakın (2012), 2000- 2010 yılları arasında Türkiye'de faaliyet gösteren yatırım fonlarının Treynor, Sharpe ve Jensen oranları ile analizini yapmışlar, analiz sonucunda kriz dönemleri dikkate alındığında A tipi fonların kötü performans gösterdiğini, B tipi fonların ise 2001-2009 dönemi içinde başarılı olduğunu tespit etmişlerdir.

Uyar ve Gökçe (2015), 2005-2009 tarihleri arasında BIST' de işlem gören bankacılık sektörü hisse senetlerini Sharpe ve Jensen oranı ile inceledikleri çalışmalarında Sharpe oranı ile yapılan analizde değerlerin negatif çıktığını bunun kriz etkisinden kaynaklandığı, Jensen oranı ile yaptıkları analizde pozitif değerlere ulaştıklarını piyasa getirisine göre yüksek getiri sağladıklarını tespit etmişlerdir.

Verma ve Hirpara (2016), 2015 yılı NIFTY 50 hisse senetlerini Sharpe, Jensen ve Treynor rasyoları kullanarak incelemişlerdir. Sharpe oranına göre portföy ve piyasa getirileri en düşük, Treynor ölçütüne göre portföy getirilerinin en yüksek ve pozitif getirileri, piyasa getirilerinin ise en düşük ve negatif getiri verdiklerini tespit etmişlerdir. Ayrıca piyasa yatırımlarının çok riskli olduğu bu sebeple yatırımcıların bu riskli yatırımdan kaçınmalarını vurgulamışlardır.

İpekten vd. (2020), 2013- 2017 yılları arasında Türkiye'de faaliyet gösteren 30 adet A tipi yatırım fonlarının performanslarını Sharpe, Treynor ve Jensen performans oranları ile analiz etmişlerdir. Çalışma sonucunda, Sharpe oranında Altın fonlarının performansının daha iyi olduğunu, değişken fonların ise performanslarının en düşük olduğu tespit etmişlerdir. Treynor oranında hisse senedi fonlarının performansının daha iyi olduğunu, Altın fonların ise performanslarının en düşük olduğu tespit etmişlerdir. Jensen endeksinde ise Altın fonlarında Yapı Kredi fonunun performansının daha iyi olduğunu ve Altın fonlarında FIBBA fonunun performanslarının en düşük olduğunu tespit etmişlerdir.

Özer ve Çömlekçi (2020), 2013-2020 yılları arasında Türkiye'de işlem gören hisse senedi şemsiye fonunu Sharpe oranı, Treynor oranı ve Jensen oranları ile analiz etmişlerdir. Analiz sonucunda Sharpe oranına ve Jensen Alfa değerine göre en yüksek performans değeri teknoloji portföyünde iken Treynor oranı açısından en yüksek performans değerinin yabancı hisse portföyüne ait olduğunu ve odaklanma portföyüne ait Sharpe oranı, Treynor oranı ve Jensen Alfa değeri çeşitlendirme portföyüne göre daha yüksek olduğu sonucuna ulaşmışlardır. Elde ettikleri sonuçlardan hareketle odaklanma portföyünün performansının, çeşitlendirme portföyüne göre daha yüksek olduğunu ve ayrıca odaklanma stratejileri arasında teknoloji odaklı fonların ve yabancı hisse senedi odaklı fonların performansının ve getirisinin diğer stratejilere göre daha yüksek olduğunu öne sürmüşlerdir.

Çalışmada kullanılan Omega Oranı ile ilgili literatür incelendiğinde ise; Kazemi, Schneeweis ve Gupta (2003), Shadwick ve Keating,'in Omega dedikleri yeni bir performans ölçüsü kullandıklarını belirtmiştir. Yeni bir performans ölçütü olan Omeganın, normalde dağıtılmış getiri dağılımları olmayan yatırımlara uygulandığında birçok geleneksel performans ölçüsünün 
yetersizliğini gidermek amacıyla geliştirildiğini ve diğer performans ölçümlerinden farklı olarak Omeganın, tüm getiri dağılımını hesaba katmak amacıyla geliştirildiğini vurgulamışlardır.

Botha (2007), 1999 yılından itibaren 90 aylık dönemde Güney Afrika hedge fonları üzerinden inceledikleri çalışmalarında Omega oranını, hem Sharpe hem de Sortino oranları ile karşılaştırmıştır. Elde ettiği bulgulara göre Omega oranının her durumda, üstün ölçü olarak ortaya çıktı̆̆ını ifade etmiştir.

Gilli vd. (2011), 1998-2008 (Mart) yılları arasında Dow Jones STOXX ‘da işlem gören 500 şirkete uyguladıkları çalışmalarında, Omega portföyleri getirilerde olumlu bir asimetri sergilemiş ayrıca portföylerde kısa pozisyonlara izin verilmesi geçmiş verilerle çalışılırken portföy performansını bozmuştur.

Kapsos vd. (2014), 11.2004- 10.2012 tarihleri arasında ABD’de işlem gören üç varlık sınıfını kapsayan üç Borsa Yatırım Fonu (ETF)'i Omega rasyosu ile inceledikleri çalışmalarında Altın ETF Sharpe ve Omega oranları ile en yüksek getiriyi sağlamıştır. Ayrıca Omega oranı maksimizasyonunun yüksek tahmin hatalarıyla ölçülen ve değişken olan beklenen getirilere duyarlı olduğunu vurgulamışlardır.

Sharma ve Mehra (2017), 04.2007-01.2012 yılları arasında Hindistan BSE endeksinde işlem gören hisse senetlerine uyguladıkları çalışmalarında Omega oranını "genişletilmiş Omega oranı optimizasyonu" ile geliştirmişler, genişletilmiş Omega oranı optimizasyon modelinden elde edilen optimum portföylerin, daha az ilişkili riske sahip olmada Omega oranı optimizasyonundan elde edilen optimum portföyler ve yüksek değerli Omega oranına karşıllk gelen ortalamadan optimum portföyler üzerinde iyileștirdiğini göstermişlerdir.

Guastaroba vd. (2016), 2005 yilında FTSE 100 endeksini oluşturan 100 menkul klymetin haftalık getirilerini; ikinci modelde ise Hong Kong, Almanya, Birleşik Krallık, ABD ve Japonya ülkelerine ait 8 endeks verilerini kullanarak Omega rasyosunu hesaplamışlardır. Analiz sonucunda, ilk modelin daha iyi bir performans gösterdiğini yalnız ikinci modelle daha yüksek getiri performansı sağladıklarını tespit etmişlerdir.

Uyar ve Çağlak (2019), 2012-2016 yılları arasında BIST’ de işlem gören hisse senetlerine Omega rasyosunu uyguladıkları çalışmalarında Omega rasyosunun diğer performans ölçütlerinden farklı olarak bir üstünlüğü olmadığı sonucuna ulaşmışlardır.

Kanuri ve Hanby (2020), 01.1997 -08.2018 ylları arasında Thomson Reuters Risk Sermayesi ve Thomson Reuters Satın Alma endekslerini ABD hisse senetleri ve tahvilleriyle karşılaştırmışlardır. Sharpe oranını, Sortino oranını ve Omega oranını kullanarak yaptıkları analizlerinde, PE endekslerinin, hem hisse senetleri hem de tahvillerle karşılaştırıldığında daha riskli olduğunu ileri sürmüşlerdir. Her iki PE endeksinin de ABD hisse senetlerinden daha yüksek, ABD tahvillerinden daha düşük bir Sortino oranına sahip olduğunu savunmuşlardır.

Literatür incelendiğinde farklı finansal varlıkların performanslarını belirlemek için kullanılan bir çok yöntem mevcuttur. 2002 yılında literatüre giren Omega Rasyosunu inceleyen çalışmalar değişken beklenen getiri olasılığına imkan vermesi en üstün yanının olduğunu 
vurgulamışlardır. Bu çalışmada farklı beklenen getiri durumlarında hisse senedi şemsiye fonlarının performanslarında değişiklik olup olmadığı araştırılmıștır.

\section{VERİ VE YÖNTEM}

\section{Çalışmanın Verileri}

Çalışmada Türkiye'de Ocak 2016- Aralık 2020 yılları arasında TEFAS'da işlem gören 48 adet hisse senedi şemsiye fonlarının 5 yıllık günlük fiyat verilerinden günlük getiriler hesaplanmış ve aylık getirilere çevrilerek çalışmada kullanılmıştır. Bu getiriler ile fonların performanslarını incelenmiş ve performans sıralaması yapılmıştır. Menkul kıymet yatırım fonu olan hisse senedi şemsiye fonları kullanılarak elde edilmiş olan veri seti, Türkiye Elektronik Fon Dağıtım Platformu (TEFAS)'da yer alan 66 adet hisse senedi şemsiye fonunu kapsamaktadır. Ancak son 5 yıllık kesintisiz verisine ulaşılamayan 18 fon çalışma kapsamına dâhil edilmemiştir.

\section{Çalışmanın Yöntemi}

Keating ve Shadwick (2002a), "An Introduction to Omega" adlı çalışmalarında performans ölçümünde getiri dağılımının ortalama ve varyans varsayımında hatalara sebep olması sonucu Omega Oranının geliştirildiğini belirtmişlerdir.

Omega oranı belirlenen bir seviye için (eşik seviyesi) olabilecek toplam olasılık ağırlıklı kazanç ve kayıpların oranlaması ile ölçülmektedir. Belirlenen seviye yatırımcının en az kabul edeceği getiri düzeyi olarak belirlenir ve bu düzeyin altında kalan (risk, kayıp) ve üzerine çıan (ödül, kazanç) tüm getirilerin değerlerini dikkate almaktadır.

Bu değer (Minimum Acceptable Return) MAR yani minimum kabul edilebilir getiri olarak tanımlanır. Omega oranı MAR ile yatırımların farklı getiri dağılımlarıyla karşılaştırarak faydalı istatistiksel yaklaşımlar sağlamaktadır (Chen vd. 2002). Yatırımcının belirlediği bir getiri düzeyinin üstündeki yatırım sonucunun kümülatif olasılığının, yatırımcının belirlediği bir getiri düzeyinin altındaki bir yatırım sonucunun kümülatif olasılık oranı ile formüle edilmiştir (Steinki ve Mohammad, 2015). Omega oranı formülü (Keating and Shadwick, 2002b);

$$
\Omega(r)=\frac{\int_{r}^{b}(1-F(X)) d x}{\int_{a}^{r} F(x) d x}
$$

$\Omega$ Omega oranı, $\mathrm{r}$ eşik değer (MAR), F kümülatif getiri dağılımı a ve $\mathrm{b}$ ise getiri aralığını temsil etmektedir. $\Omega(\mathrm{r})$ sayısı, $\mathrm{r}$ eşiğine göre kazançların kayıplara olasılık ağırlıklı oranıdır. Bir yatırımın olasılık dağılımının Omega oranı, belirlenen değerin üzerinde olanları kazanç olarak belirleyip bu miktarların olasılıkları ile çarpılarak, belirlenen değerin altında kalanları kayıp olarak kabul edilen miktarların toplamının olasılıkları ile çarpımına bölünmesine karşılık gelir (Keating 2002a). Herhangi bir getiri seviyesi için $\Omega(r)$ sayısı, r eşiği ile ilgili karların zararlara olasılıklı ağırlıklı oranıdır. Eğer r ortalama getiri değeri olursa Omega 1 değerini alır. Hesaplanan Omega oranı ne kadar büyükse finansal varlığın kazancı o kadar büyüktür bu sebeple performans ölçümünde yüksek Omega rasyosuna sahip finansal varlık üst sırada yer alacaktır. Ayrıca 
hesaplanan Omega rasyosu değerleri pozitif değer almaktadır (Thompson, 2008). Omega rasyosunun sinırlılıkları (Steinki ve Mohammad, 2015);

Omega değerinin yüksek olması; Omega rasyosu $\Omega>1$ olursa MAR $<\mu$ olmaktadır. Yani yatırımcı tarafından belirlenecek eşik değer dağılımın ortalamasından düşük olursa Omega rasyosu birden yüksek olacaktır. Omega rasyosu 1'e eşit olması durumu; $\Omega=1 \mathrm{MAR}=\mu$ değerini alır. Bu durumda eşik değer getiri dağılımının ortalaması olarak ayarlanırsa Omega rasyosu 1' e eşit olacaktır. Omega rasyosunun sıfır olma durumunda ise, $\Omega=0$ tüm getiriler $<$ MAR olmaktadır. Eşik değerinin yüksek olması tüm getiri değerlerini gerisinde bırakacak yani eşik değerinin yüksek belirlenmesi o değerin kazanılmasını zorlaştıracak elde etme olasılığını düşürecektir bu sebeple de oranı sıfır değerini alacaktır.

Omega oranı, varlık getirilerinin herhangi bir dağılımı için kullanılabilir (Kapsos vd., 2014). Omega oranı doğrudan gözlemlenen dağılımdan hesaplandığı için örnekleme belirsizliğinden etkilenmez. Normal dağılım varsayımına bağlı olmadığı için normal dağılım olmayan getirileri olan finansal varlıkların performans ölçümlerinde, finansal strateji sonuçları değerlendirmekte ve yönetici performans sıralamaları gibi durumlarda önerilmektedir. Yalnızca Omega oranı hesaplarken kullanılan eşik değerinin tek olmamasını farklı değerlerde eşik değerler belirleyerek analizin daha verimli değerlendirilmesini sağlayabilecektir (Steinki ve Mohammad, 2015).

\section{BULGULAR}

Çalışmada kullanılan 2016-2020 yılları arasında 48 adet hisse senedi şemsiye fonlarının performanslarını; yatırımcının beklediği getiri oranlarını \%1 getiri oranından $\% 10$ getiri oranına kadar eşik değer olarak belirleyerek Omega rasyosu kullanılarak analiz edilmiştir (Uyar ve Çaylak, 2019; Sharma ve Mehra, 2017). Çalışmada hisse senedi fonlarının günlük getiriler hesaplandıktan sonra aylık kümülatif getirileri hesaplanarak her bir fonun Omega oranı eșik değerlerine göre hesaplanmıştır. Tablo 1'de her 48 adet hisse senedi şemsiye fonu için hesaplanan Omega oranları verilmiştir.

Tablo 1: Hisse Senedi Şemsiye Fonları Omega Oranı Hesaplamaları

\begin{tabular}{|l|l|l|l|l|l|l|l|l|l|l|}
\hline & $1 \%$ & $2 \%$ & $3 \%$ & $4 \%$ & $5 \%$ & $6 \%$ & $7 \%$ & $8 \%$ & $9 \%$ & $10 \%$ \\
\hline AAV & 5,299879 & 2,748819 & 1,559595 & 0,929463 & 0,587673 & 0,377791 & 0,235806 & 0,133359 & 0,06906 & 0,04632 \\
\hline ACK & 1,71554 & 1,076947 & 0,694 & 0,454826 & 0,296185 & 0,19334 & 0,129774 & 0,083838 & 0,053563 & 0,033051 \\
\hline ADP & 0,746316 & 0,576199 & 0,444463 & 0,34194 & 0,260353 & 0,199673 & 0,15331 & 0,116879 & 0,086732 & 0,062849 \\
\hline AFA & 0,294866 & 0,218927 & 0,165706 & 0,131709 & 0,104991 & 0,083137 & 0,066942 & 0,055337 & 0,045465 & 0,036964 \\
\hline AFS & 0,258654 & 0,187469 & 0,138068 & 0,10176 & 0,074486 & 0,052959 & 0,036953 & 0,025473 & 0,01767 & 0,011331 \\
\hline AFT & 0,218968 & 0,169738 & 0,133779 & 0,108118 & 0,087784 & 0,071945 & 0,058507 & 0,046964 & 0,036942 & 0,028157 \\
\hline AFV & 0,287535 & 0,211017 & 0,160379 & 0,123854 & 0,09619 & 0,075758 & 0,060306 & 0,048471 & 0,038515 & 0,030024 \\
\hline AHI & 0,329113 & 0,209976 & 0,141775 & 0,097452 & 0,068584 & 0,046648 & 0,031437 & 0,019057 & 0,009477 & 0,004699 \\
\hline AKU & 0,391494 & 0,264722 & 0,179607 & 0,123042 & 0,081822 & 0,051761 & 0,032656 & 0,022468 & 0,015976 & 0,010552 \\
\hline AK3 & 0,342076 & 0,240273 & 0,168214 & 0,115838 & 0,076964 & 0,048998 & 0,031034 & 0,020832 & 0,014705 & 0,009554 \\
\hline ALC & 0,336196 & 0,222897 & 0,148745 & 0,100348 & 0,063541 & 0,039563 & 0,025993 & 0,018743 & 0,012756 & 0,007729 \\
\hline AOY & 0,266247 & 0,200142 & 0,154303 & 0,119103 & 0,093538 & 0,076468 & 0,062848 & 0,051449 & 0,04177 & 0,033448 \\
\hline AYA & 0,15155 & 0,113669 & 0,083973 & 0,063399 & 0,046049 & 0,031674 & 0,022811 & 0,016768 & 0,15155 & 0,008257 \\
\hline DAH & 0,402134 & 0,281807 & 0,198124 & 0,138514 & 0,095904 & 0,064959 & 0,043449 & 0,030633 & 0,402134 & 0,013744 \\
\hline
\end{tabular}




\begin{tabular}{|c|c|c|c|c|c|c|c|c|c|c|}
\hline DZE & 0,385642 & 0,259521 & 0,172406 & 0,114785 & 0,073001 & 0,044405 & 0,028748 & 0,018648 & 0,385642 & 0,00746 \\
\hline EC2 & 0,255986 & 0,188651 & 0,137044 & 0,098876 & 0,07116 & 0,051062 & 0,034917 & 0,022618 & 0,015228 & 0,010058 \\
\hline EID & 0,21723 & 0,140958 & 0,084261 & 0,045507 & 0,02508 & 0,014539 & 0,007865 & 0,004986 & 0,002579 & 0,000537 \\
\hline FYD & 0,310731 & 0,21843 & 0,151089 & 0,104574 & 0,073512 & 0,05314 & 0,038361 & 0,026104 & 0,016125 & 0,009179 \\
\hline GAE & 0,417013 & 0,284964 & 0,191238 & 0,133208 & 0,090592 & 0,058549 & 0,03737 & 0,024182 & 0,016762 & 0,01123 \\
\hline GAF & 0,432421 & 0,305594 & 0,217522 & 0,155129 & 0,108575 & 0,076349 & 0,056582 & 0,041914 & 0,029684 & 0,020342 \\
\hline GBG & 0,225167 & 0,156058 & 0,113951 & 0,084131 & 0,062541 & 0,045968 & 0,0342 & 0,026934 & 0,020823 & 0,015611 \\
\hline GHS & 0,316509 & 0,225774 & 0,165027 & 0,121631 & 0,088735 & 0,066724 & 0,05059 & 0,037224 & 0,02597 & 0,016363 \\
\hline$\overline{G L 1}$ & 0,171133 & 0,114686 & 0,076486 & 0,049356 & 0,028199 & 0,015997 & 0,008703 & 0,003776 & 0,000129 & 0 \\
\hline GMR & 0,217626 & 0,142974 & 0,088053 & 0,055383 & 0,035322 & 0,021691 & 0,010827 & 0,00492 & 0,000724 & 0 \\
\hline GSP & 0,226711 & 0,149466 & 0,096597 & 0,061683 & 0,037781 & 0,020712 & 0,010547 & 0,00492 & 0,000511 & 0 \\
\hline $\mathrm{HBU}$ & 0,433308 & 0,303549 & 0,209754 & 0,149084 & 0,105626 & 0,071792 & 0,048352 & 0,031881 & 0,021126 & 0,014951 \\
\hline HVS & 0,248143 & 0,174442 & 0,122683 & 0,081662 & 0,055572 & 0,037516 & 0,025005 & 0,017492 & 0,012181 & 0,007645 \\
\hline ICF & 0,312038 & 0,208423 & 0,137505 & 0,09092 & 0,060077 & 0,038121 & 0,025746 & 0,016327 & 0,010102 & 0,00534 \\
\hline KYA & 0,407226 & 0,288934 & 0,203201 & 0,141795 & 0,099543 & 0,070082 & 0,048894 & 0,032843 & 0,021448 & 0,012871 \\
\hline MAC & 0,205761 & 0,136197 & 0,090861 & 0,056048 & 0,030108 & 0,0141 & 0,005813 & 0,001973 & 0 & 0 \\
\hline ST1 & 0,250009 & 0,164081 & 0,106702 & 0,070806 & 0,047917 & 0,032176 & 0,023078 & 0,016572 & 0,01113 & 0,006511 \\
\hline TAU & 0,744954 & 0,573098 & 0,441864 & 0,338676 & 0,256773 & 0,199328 & 0,152861 & 0,116952 & 0,088417 & 0,064158 \\
\hline TIE & 0,420594 & 0,288361 & 0,195184 & 0,137977 & 0,095043 & 0,06313 & 0,041096 & 0,027326 & 0,017837 & 0,012224 \\
\hline TI2 & 0,373846 & 0,26088 & 0,183051 & 0,124864 & 0,082131 & 0,056056 & 0,037167 & 0,024296 & 0,016436 & 0,011035 \\
\hline TI3 & 0,299854 & 0,214845 & 0,151822 & 0,104764 & 0,071128 & 0,047742 & 0,031103 & 0,017393 & 0,009519 & 0,005005 \\
\hline TKF & 0,09575 & 0,062346 & 0,041297 & 0,026524 & 0,016506 & 0,010484 & 0,007498 & 0,004983 & 0,002835 & 0,00098 \\
\hline TLH & 0,390784 & 0,28159 & 0,202941 & 0,146578 & 0,103944 & 0,073083 & 0,05208 & 0,038095 & 0,026393 & 0,016457 \\
\hline TMG & 0,250035 & 0,173615 & 0,118144 & 0,083517 & 0,061059 & 0,046386 & 0,034841 & 0,027246 & 0,021022 & 0,016109 \\
\hline TPR & 0,340882 & 0,23057 & 0,157595 & 0,104937 & 0,068259 & 0,045302 & 0,029813 & 0,019315 & 0,012144 & 0,007157 \\
\hline TTE & 0,33612 & 0,264285 & 0,210113 & 0,16587 & 0,129653 & 0,101116 & 0,079213 & 0,061477 & 0,047787 & 0,0376 \\
\hline TYH & 0,307544 & 0,209472 & 0,142224 & 0,094943 & 0,063804 & 0,04265 & 0,02585 & 0,015875 & 0,008622 & 0,00554 \\
\hline TZD & 0,355469 & 0,245544 & 0,168658 & 0,116876 & 0,08264 & 0,056749 & 0,038496 & 0,025543 & 0,016079 & 0,010797 \\
\hline YAS & 0,375074 & 0,263564 & 0,182511 & 0,123131 & 0,085794 & 0,060007 & 0,042883 & 0,030411 & 0,021454 & 0,013876 \\
\hline YAY & 0,236309 & 0,180082 & 0,139192 & 0,110487 & 0,087438 & 0,070347 & 0,057564 & 0,047278 & 0,038454 & 0,030801 \\
\hline YDI & 0,301189 & 0,209985 & 0,147905 & 0,105531 & 0,073118 & 0,049579 & 0,0333 & 0,021366 & 0,011325 & 0,004037 \\
\hline YEF & 0,41827 & 0,288356 & 0,19718 & 0,13768 & 0,094921 & 0,063031 & 0,041877 & 0,025699 & 0,017368 & 0,011802 \\
\hline YHS & 0,328688 & 0,2217 & 0,143581 & 0,091564 & 0,056852 & 0,03306 & 0,018518 & 0,010294 & 0,006146 & 0,003626 \\
\hline$\overline{\mathrm{ZPE}}$ & 0,230384 & 0,137642 & 0,074788 & 0,044409 & 0,029163 & 0,017909 & 0,010767 & 0,006169 & 0,003606 & 0,00144 \\
\hline
\end{tabular}

Tablo 1'de her bir hisse senedi fonu için farklı eşik düzeylerinde Omega rasyosu hesaplamaları verilmiştir. Thampson (2008), çalışmasında vurguladığı gibi çalışma sonucunda elde edilen Omega rasyolarının negatif değerler almadığı görülmektedir. Steinki ve Mohammad (2015), çalışmasında vurguladığı Omega rasyosu varsayımlardan biri olan Omega rasyosunun sıfır değerini alması, analizde kullanılan fonlardan MAC \%9, GL1, GMR, GSP, MAC fonları \%10 eşik değerinde Omega rasyoları 0 değerini almıştır. Bu fonlar eşik değerinin altında kalmıştır.

Analiz sonuçlarının her bir eşik değerine göre 48 adet fonun Omega rasyoları verilerek aşağıda verilen şekillerde incelenmiştir. 


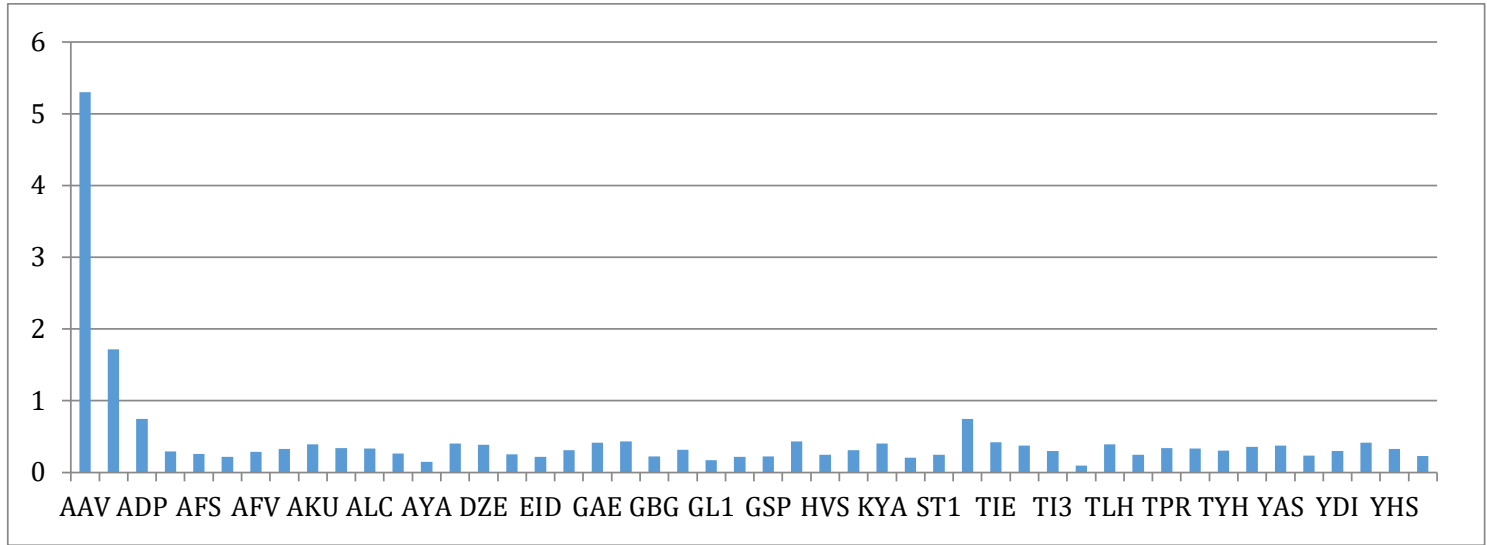

Şekil 1: \%1 Eşik Değerine Göre Hisse Senedi Şemsiye Fonlarının Sıralanması

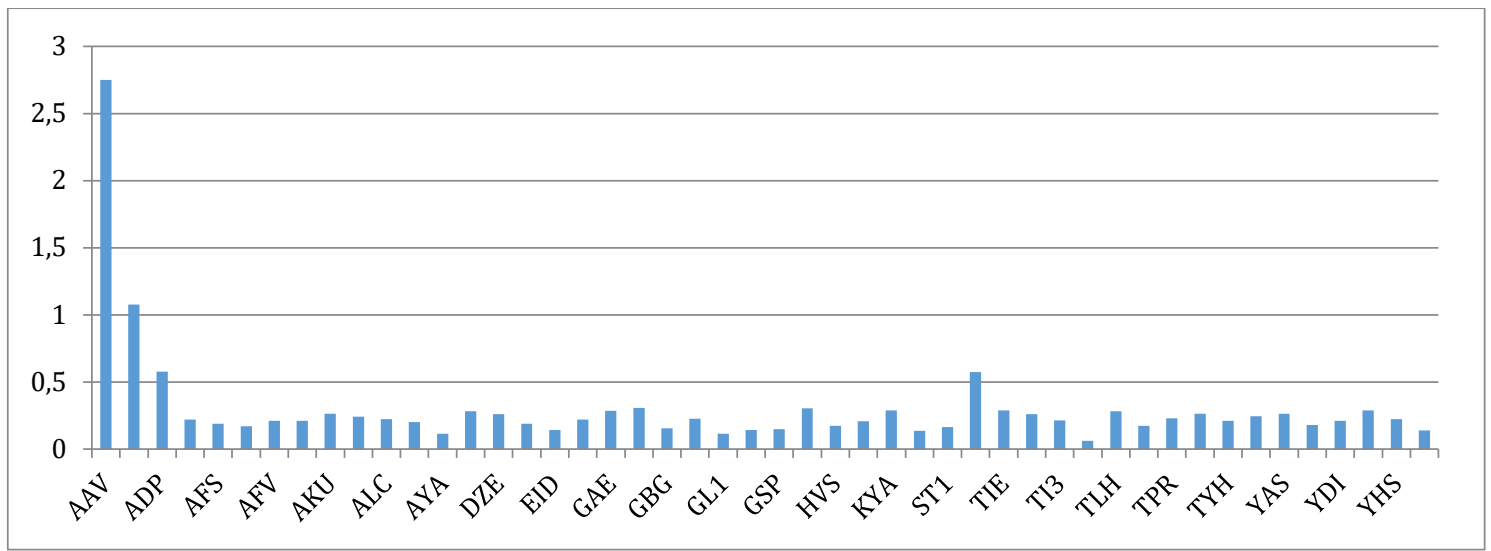

Şekil 2: \%2 Eşik Değerine Göre Hisse Senedi Șemsiye Fonlarının Sıralanması

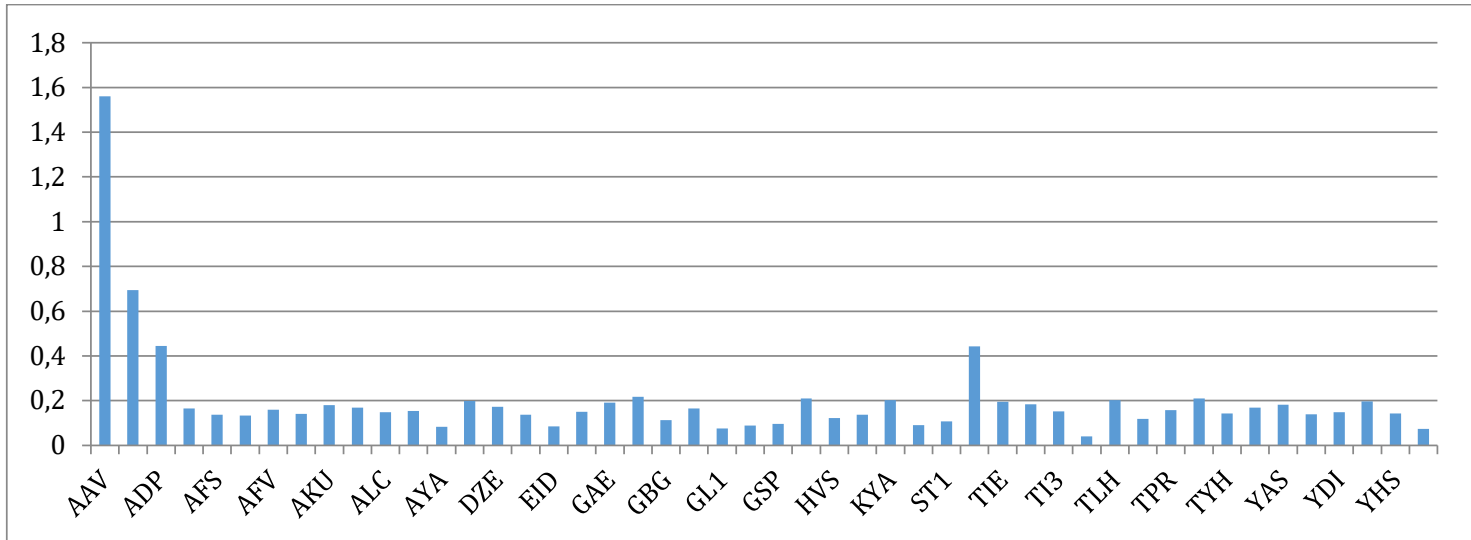

Şekil 3: \%3 Eşik Değerine Göre Hisse Senedi Şemsiye Fonlarının Sıralanması 


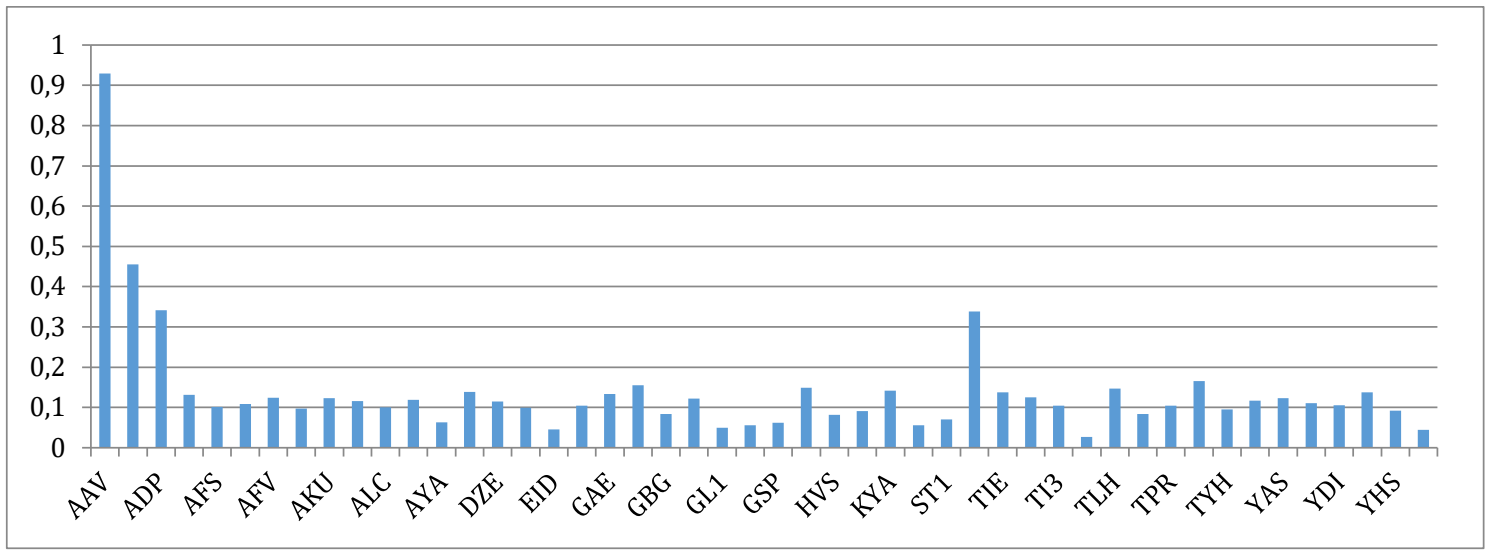

Şekil 4: \%4 Eşik Değerine Göre Hisse Senedi Şemsiye Fonlarının Sıralanması

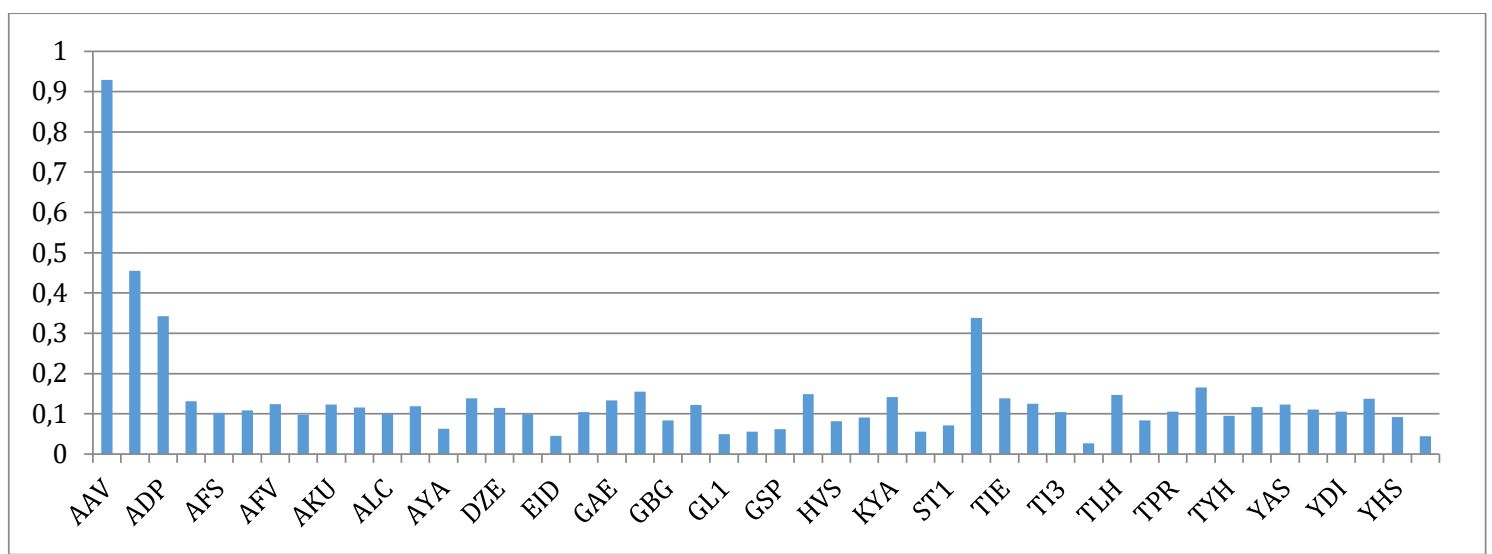

Şekil 5: \%5 Eşik Değerine Göre Hisse Senedi Şemsiye Fonlarının Sıralanması

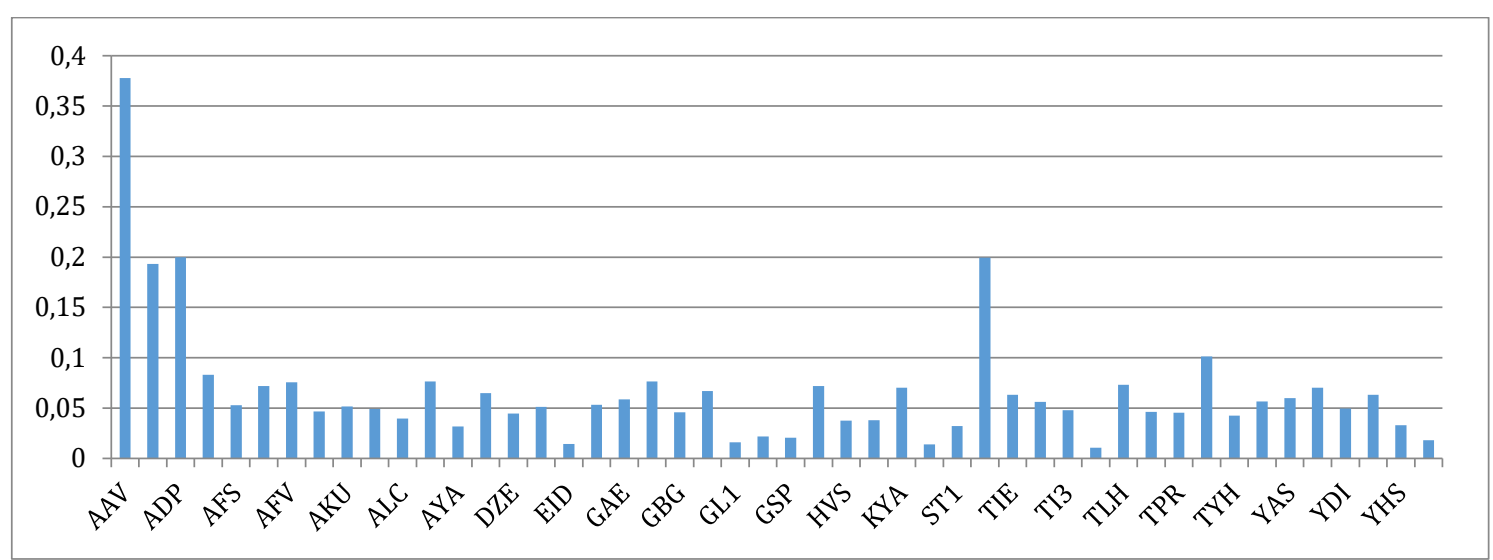

Şekil 6: \%6 Eşik Değerine Göre Hisse Senedi Şemsiye Fonlarının Sıralanması 
Hisse Senedi Yatirim Fonlarinin Omega Performans Analizi

Omega Performance Analysis Of Share Funds

0,25

0,2

0,15

0,05

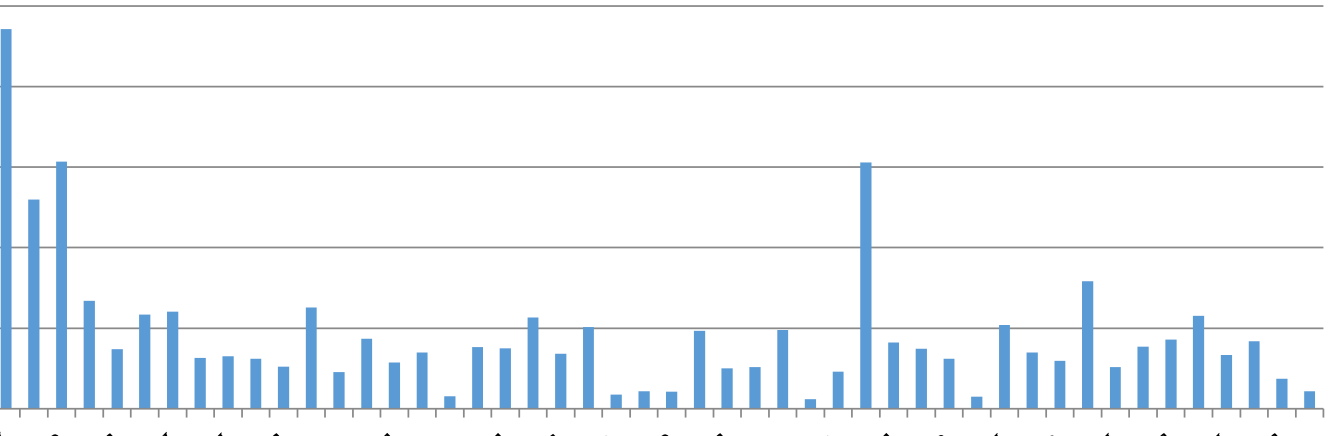

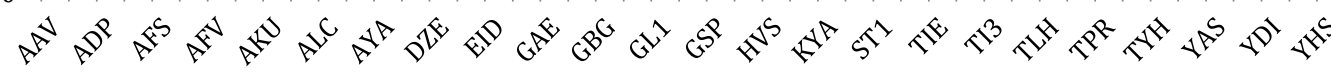

Şekil 7: \%7 Eşik Değerine Göre Hisse Senedi Şemsiye Fonlarının Sıralanması

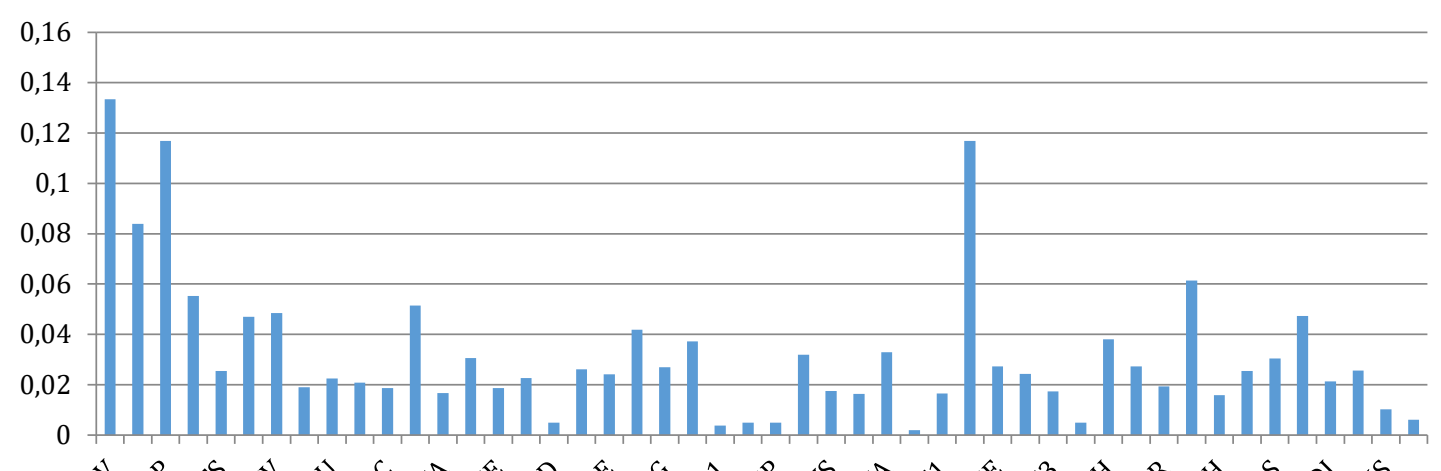

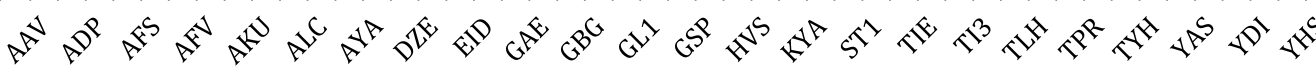

Şekil 8: \%8 Eşik Değerine Göre Hisse Senedi Şemsiye Fonlarının Sıralanması

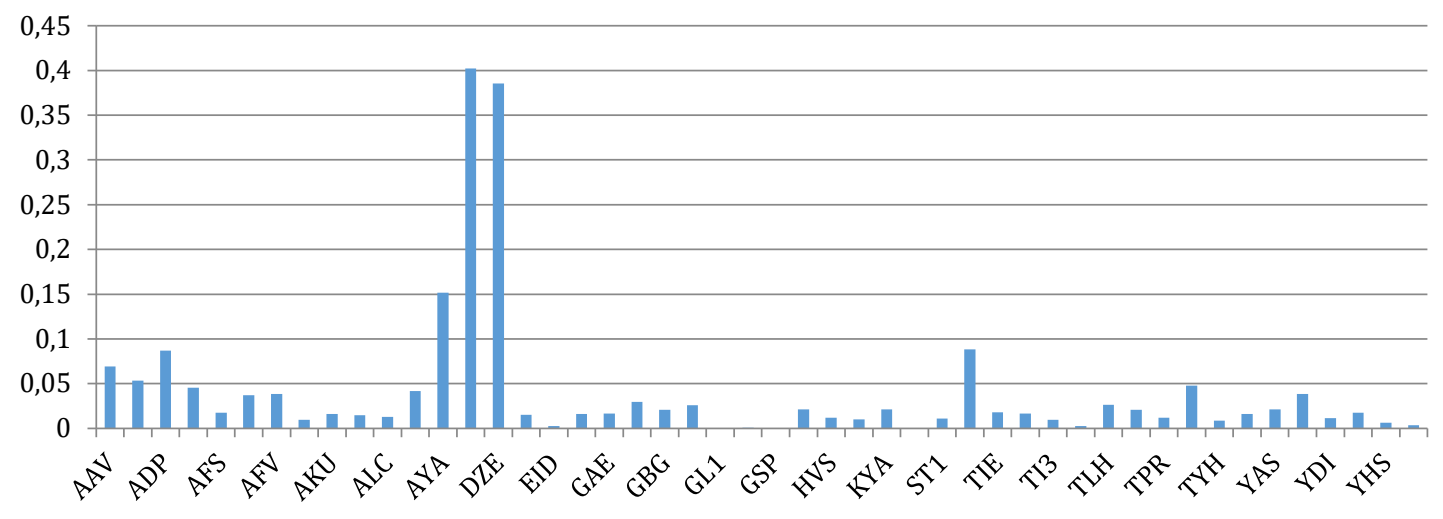

Şekil 9: \%9 Eşik Değerine Göre Hisse Senedi Şemsiye Fonlarının Sıralanması

60 


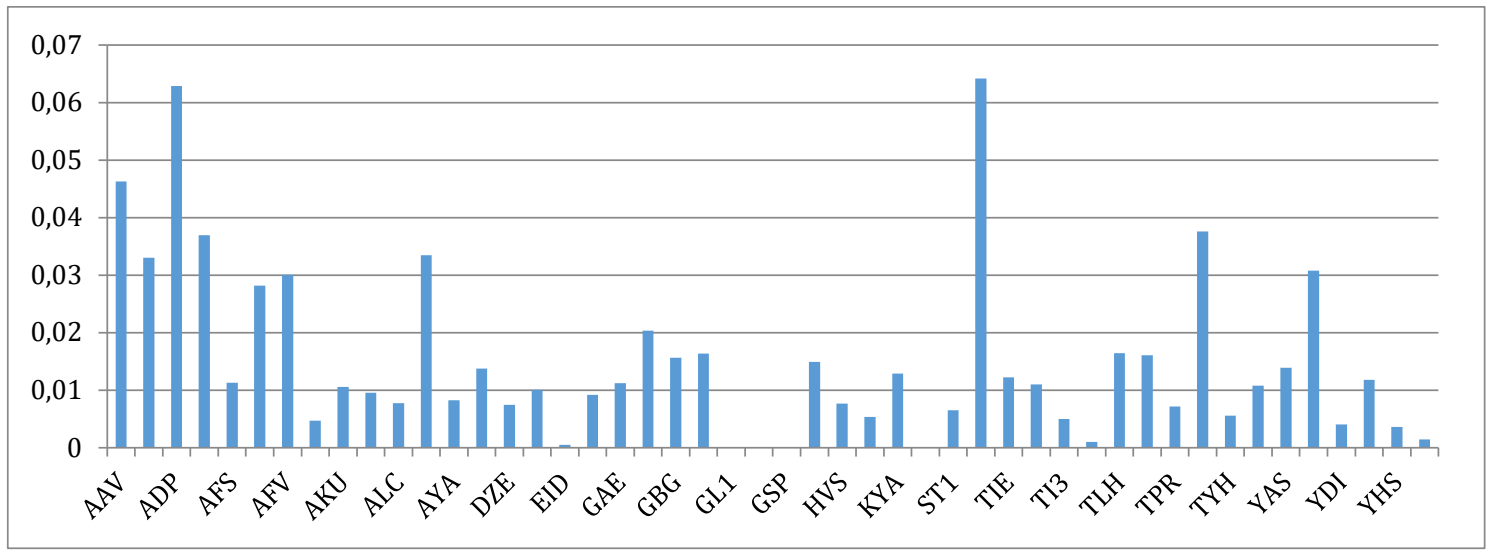

Şekil 10: \%10 Eşik Değerine Göre Hisse Senedi Şemsiye Fonlarının Sıralanması

Hisse senedi şemsiye fonlarının Omega değerlerine ilişkin şekiller incelendiğinde $\% 1, \% 2$, \%3, \%4, \%5, ve \%6 eşik değerlerinde AAV hisse senedi şemsiye fonu en yüksek Omega Rasyo değerine sahipken TKF hisse senedi yatırım fonu ise en düşük Omega rasyo değerine sahiptir. Şekil 7 ve Şekil 8 incelendiğinde, \%7 ve \%8 eşik değerinde en yüksek Omega değerine sahip hisse senedi şemsiye fonunun değişmediği (AAV), fakat en düşük Omega rasyo değerine sahip fonun ise MAC olduğu görülmektedir.

Şekil 9'de incelendiğinde \% 9 eşik değerinde 0,402 Omega rasyo değeri ile DAH hisse senedi şemsiye fonun en yüksek, 0 Omega değeri ile MAC hisse senedi şemsiye fonunun en düşük Omega rasyosuna sahip şemsiye fonu olduğu tespit edilmiştir.

Şekil 10'de görüldüğü gibi \%10 eşik değerinde 0,064 Omega rasyo değeri ile TAU hisse senedi şemsiye fonu en yüksek, 0 Omega değeri ile GMR, GSP,GL1 ve MAC hisse senedi şemsiye fonlarının ise en düşük Omega oranına sahip șemsiye fonları olduğu görülmektedir.

Omega rasyoları en yüksek ve en düşük hisse senedi şemsiye fonları gözlemledikten sonra Omega rasyosu en yüksek olan ilk 10 șemsiye fonu ve bu on fonun sıralaması Tablo 2'de verilmiştir. 
Tablo 2: Omega Performans Değerlendirme Tekniğine göre En iyi 10 Hisse Senedi Fonu

\begin{tabular}{|c|c|c|c|c|c|c|c|c|c|c|c|}
\hline $\begin{array}{c}\text { Eşik } \\
\text { Değer }\end{array}$ & Siralama & 1. & 2. & 3. & 4. & 5. & 6. & 7. & 8. & 9. & 10. \\
\hline \multirow[t]{2}{*}{$\% 1$} & Şirket & AAV & ACK & ADP & TAU & HBU & GAF & TIE & YEF & GAE & KYA \\
\hline & Omega Oranı & 5,299 & 1,715 & 0,746 & 0,745 & 0,433 & 0,432 & 0,420 & 0,418 & 0,417 & 0,407 \\
\hline \multirow[t]{2}{*}{$\% 2$} & Şirket & AAV & ACK & ADP & TAU & GAF & $\mathrm{HBU}$ & KYA & TIE & YEF & GAE \\
\hline & Omega Oranı & 2,749 & 1,077 & 0,576 & 0,573 & 0,306 & 0,304 & 0,289 & 0,288 & 0,288 & 0,285 \\
\hline \multirow[t]{2}{*}{$\% 3$} & Şirket & AAV & ACK & ADP & TAU & GAF & TTE & $\mathrm{HBU}$ & KYA & TLH & DAH \\
\hline & Omega Oranı & 1,560 & 0,694 & 0,444 & 0,442 & 0,218 & 0,210 & 0,210 & 0,203 & 0,203 & 0,198 \\
\hline \multirow[t]{2}{*}{$\% 4$} & Şirket & AAV & ACK & ADP & TAU & TTE & GAF & $\mathrm{HBU}$ & TLH & KYA & DAH \\
\hline & Omega Oranı & 0,929 & 0,455 & 0,342 & 0,339 & 0,166 & 0,155 & 0,149 & 0,147 & 0,142 & 0,139 \\
\hline \multirow[t]{2}{*}{$\% 5$} & Şirket & AAV & ACK & ADP & TAU & TTE & GAF & $\mathrm{HBU}$ & TLH & KYA & DAH \\
\hline & Omega Oranı & 0,257 & 0,260 & 0,588 & 0,130 & 0,105 & 0,094 & 0,296 & 0,087 & 0,096 & 0,088 \\
\hline \multirow[t]{2}{*}{$\% 6$} & Şirket & AAV & ADP & TAU & ACK & TTE & AFA & $\mathrm{AOY}$ & GAF & $\mathrm{AFV}$ & TLH \\
\hline & Omega Oranı & 0,378 & 0,200 & 0,199 & 0,193 & 0,101 & 0,083 & 0,076 & 0,076 & 0,076 & 0,073 \\
\hline \multirow[t]{2}{*}{$\% 7$} & Şirket & AAV & ADP & TAU & ACK & TTE & AFA & AOY & $\mathrm{AFV}$ & AFT & YAY \\
\hline & Omega Oranı & 0,236 & 0,153 & 0,153 & 0,130 & 0,079 & 0,067 & 0,063 & 0,060 & 0,059 & 0,058 \\
\hline \multirow[t]{2}{*}{$\% 8$} & Şirket & AAV & TAU & ADP & ACK & TTE & AFA & AOY & $\mathrm{AFV}$ & YAY & AFT \\
\hline & Omega Oranı & 0,133 & 0,117 & 0,117 & 0,084 & 0,061 & 0,055 & 0,051 & 0,048 & 0,047 & 0,046 \\
\hline \multirow[t]{2}{*}{$\% 9$} & Şirket & DAH & DZE & AYA & TAU & ADP & AAV & ACK & TTE & AFA & AOY \\
\hline & Omega Oranı & 0,402 & 0,386 & 0,152 & 0,088 & 0,087 & 0,069 & 0,054 & 0,048 & 0,045 & 0,042 \\
\hline \multirow[t]{2}{*}{ \%10 } & Şirket & TAU & ADP & AAV & TTE & AFA & AOY & ACK & YAY & $\mathrm{AFV}$ & AFT \\
\hline & Omega Oranı & 0,064 & 0,063 & 0,046 & 0,038 & 0,037 & 0,033 & 0,033 & 0,031 & 0,030 & 0,028 \\
\hline
\end{tabular}

Tablo 2'de görüldüğü üzere $\% 1$ 'den $\% 10$ ' kadar farklı eşik değerlerinde en yüksek Omega rasyolarına göre sıralanmış ilk 10 hisse senedi șemsiye fonu sıralaması yapılmıştır. \%1'den \%8' eşik değerine kadar AAV yatırım fonunun en yüksek Omega değerine sahip olduğu görülmektedir. \%9 eşik değerinde DAH hisse senedi şemsiye fonu, \%10 eşik değerinde ise TAU hisse senedi şemsiye fonu en yüksek Omega değerine sahip olmuştur.

\section{SONUÇ}

Keating ve Shadwick (2002a) tarafından ortaya atılan Omega rasyosu daha fazla sayıda finansal varlığı değerlendirmeye olanak tanıması ve farklı risk ya da beklenen getiri seviyesine diğer bir ifadeyle eşik değerlerine göre incelenmeye yardımcı olmaktadır (Kapsos, 2014). Omega rasyosu yüksek moment ve ortalama varyans ölçümlerini dikkate alması ve veri dağılımlarının normal dağılıp dağılmamasını dikkate almaması ve hiçbir belirsizliği içermemesi sebebiyle diğer performans ölçümlerine göre daha iyi performans sıralaması yapmaktadır (Keating ve Shadwick, 2002b). Yatırımcıların risk seviyesine göre ya da bekledikleri getiri değerlerine göre rasyo hesaplaması yatırımcıların kazanç ya da kayıplarını daha iyi görmelerini sağlamaktadır. Botha (2007), Gilli (2011), Guostaroba vd. (2016) ve Fong (2016) çalışmaları Omega rasyosunun üstün bir performans değerleme ölçütü olduğunu vurgulamışlardır. 
Yatırım fonları bireysel yatırımlara göre daha profesyonel yönetildikleri için yatırımcıların dikkatini çekmektedir. Özellikle gelişmiş ülkelerde yatırımcıların önemli tercihlerinden birisidir. Yatırım fonları, bireysel ya da kurumsal yatırımcıların fonlarından oldukça büyük fon havuzlarına sahip olmaları daha fazla finansal varlık çeşitliliği ve/veya daha fazla finansal varlık sayısı ile yatırımı kapsamaktadır, bu sebeple riski tolere etmek ya da bireysel yatırıma göre daha fazla getiri sağlaması sayesinde yatırımcılar bu fonlara yönelmektedir.

Çalışmada kullanılan 2016-2020 dönemi içerisinde kesintisiz verisine ulaşılan 48 hisse senedi şemsiye fonu ile yapılan Omega performans analiz sonucunda hisse senedi şemsiye fonları performans sıralaması yapılmıştır. Fon performansları açısından bakıldığından ilk 10 sıralamasında birinci sırada yer alan hisse senedi şemsiye fonlarından, eşik değeri olarak belirlenen beklenen getiri oranı \%1'den \%8'e kadar AAV fonunun en yüksek Omega değerine sahip olduğu görülmektedir. Yalnız yatırımcının beklenen getiri oranı \%9'a çıkarsa AAV fonu 6. sıraya gerilemekte, $\% 10$ beklenen getiri oranına çıkarsa 3. sırada yer almaktadır. $\% 9$ eşik değerinde DAH hisse senedi şemsiye fonu ise 1 . sırada yer alırken, bu hisse senedi şemsiye fonu $\% 1, \% 2, \% 6, \% 7, \% 8$ ve $\% 10$ beklenen getiri oranlarında siralamaya girememektedir. $\% 3$ beklenen getiri oranında 10 . sırada, $\% 4$ beklenen getiri oranında ise 5 .sırada yer almaktadır. $\% 10$ eşik değerinde ise TAU hisse senedi şemsiye fonu en yüksek Omega değerine sahip olmuştur. \%1, $\% 2, \% 3, \% 4, \% 5$ ve $\% 9$ beklenen getiri oranlarında 4 sırada yer alırken $\% 8$ ' de ikinci sırada, $\% 6$ ve \%7'de 3.sırada yer almıştır. Farklı eşik değerlerinde farklı sıralamalar vermesi, değişken beklenen getirilere duyarlı olduğu sonucu elde edilmiş ve Kapsos vd. (2014) ve Uyar ve Çağlak (2019)'un çalışmalarıyla benzer sonuçlar elde edilmiştir.

Omega rasyosunun eșik değeri adı verilen kayıp ya da kazanç sınırı olarak belirli değerlerde sıralamaya imkân vermesi yatırımcıların daha detaylı sıralama yapmasına olanak sağlamaktadır. Analiz sonuçlarında farklı beklenen getiri oranlarında farklı yatırım fonlarının daha yüksek Omega değerlerine sahip olduğu tespit edilmiştir. Bir fonun ise farklı beklenen getiri oranlarında farklı sıralamada yer alabileceği görülmüştür.

$\mathrm{Bu}$ doğrultuda yatırımcıların fon tercihinden önce beklenen getiri oranını belirlemeleri ve fon tercihlerinde bu oranı dikkate almaları gerektiği savunulabilir. Öte yandan Omega rasyosundaki değişimlere göre yatırımcıların risk ve getiri tercihlerini daha rasyonel olarak şekillendirebilecekleri ileri sürülebilir. $\mathrm{Bu}$ analiz farklı ülke piyasalarında, farklı finansal varlıkların başarı performanslarına da uygulanabilir. Yatırımcılar açısından diğer performans ölçüm kriterlerine göre değerlendirme yaparken Omega rasyosunun da ele alınması daha kapsamlı analiz yapabilmelerini ve daha kolay yorum yapabilmelerine olanak sağlayacağı düşünülmektedir. 


\section{KAYNAKLAR}

Botha, M. (2007). A Comparison Of South African Hedge Fund Risk Measures. The South African Journal of Economics. 75(3), 459-477.

Chaudhry A. ve Johnson H. L. (2008). The Efficacy of the Sortino Ratio and Other Benchmarked Performance Measures Under Skewed Return Distributions. Australian Journal of Management. 32.

Chen, P. vd. (2002). Portfolios with Hedge Funds and Other Alternative Investments. Introduction to a Work in Progress.

Dumanoğlu, S. ve Ergül, N. (2010). İMKB'de İşlem Gören Teknoloji Şirketlerinin Mali Performans Ölçümü. Muhasebe ve Finansman Dergisi. (48), 101-111.

Farinelli S. vd. (2008). Beyond Sharpe ratio: Optimal asset allocation using different performance ratios. Journal of Banking \& Finance. 32(10), 2057-2063.

Friend, I., Brown, F. E., Herman, E. S., ve Vickers, D. (1962). A study of mutual funds. US Government Printing Office, Washington, DC.

Fong W. M. (2016). Stochastic dominance and the Omega ratio. Finance Research Letters. 17, 7-9.

Gilli, M. vd. (2011). Constructing 130/30-portfolios with the Omega ratio. Journal of Asset Management. 12(2), 94-108.

Guastaroba G. vd. (2016). Linear Programming Models Based On Omega Ratio For The Enhanced Index Tracking Problem. European Journal Of Operational Research 3(251), 938-956.

Hodges, C. vd. (2003). Beta, the Treynor ratio, and long-run investment horizons. Applied Financial Economics. 13(7), 503-508.

Hübner, G. (2005). The Generalized Treynor Ratio. Review of Finance. 9(3), 415-435.

İpekten, N. vd. (2020). Türkiye'de A Tipi Yatırım Fonlarının Performans Analizi (01/201312/2017). Ömer Halisdemir Üniversitesi İktisadi ve İdari Bilimler Fakültesi Dergisi. 13 (3), 462-476.

Jensen, M. C. (1968). The performance of mutual funds in the period 1945-1964. The Journal of Finance, 23, 389-416.

Kahraman, D. (2006). Menkul Kıymet Yatırım Fonları Performansının Hayatta Kalana Bağlı Yanlılı̆̆: Gelişmekte Olan Piyasa Fonlarında Türlere Göre İnceleme. Afyon Kocatepe Üniversitesi İktisadi ve İdari Bilimler Fakültesi Dergisi. 8(2), 175-189.

Kanuri, S. ve Hanby, M. (2020). Private Equity (PE) Performance in The United States. Journal of Applied Business and Economics. 22(1), 36-45.

Kapsos M. vd. (2014). Worst-case robust Omega ratio. European Journal of Operational Research. 234(2), 499-507.

Kazemi, H., Schneeweis, T., \& Gupta, B. (2004). Omega As A Performance Measure. Journal Of Performance Measurement., 8, 16-25. 
Keating C. ve Shadwick W.F. (2002a). An Introduction to Omega. The Finance Development Centre.

Keating, C. ve Shadwick, W. F. (2002b). A universal performance measure. Journal of performance measurement. 6(3), 59-84.

Özer, A. ve Çömlekçi, İ. (2020). Odaklanma Stratejisi Ve Çeşitlendirme Stratejisi İzleyen Fonların Performanslarının Karşılaştırılması. Elektronik Sosyal Bilimler Dergisi. $19(76)$, 2012-2023.

Samırkaş, Ö. ve Düzakın, D. (2012). Türkiye'deki A Ve B Tipi Yatırım Fonlarının Performans Analizi. Çukurova Üniversitesi Sosyal Bilimler Enstitüsü Dergisi, 21 (3), 391-410.

Sharma, A. ve Mehra, A. (2017). Extended Omega ratio optimization for risk-averse investors. International Transactions in Operational Research. 24(3), 485-506.

Sharpe, W. F. (1966). Mutual fund performance. The Journal of business. 39(1), 119-138.

Steinki, O. ve Mohammad, Z. (2015). Common Metrics for Performance Evaluation: Overview of Popular Performance Measurement Ratios. Capital Markets: Market Efficiency eJournal.

Treynor, J. L. (1965). How to rate management of investment funds. Harvard Business Review, 43, 63-73.

Thompson, R. (2008). The Measurement and Management of Foreign Exchange Risk in Emerging Markets. Feature. 21-30.

Uyar, U. ve Çağlak, E. (2019). Menkul Kıymet Performans Ölçümünde Omega Rasyosu: Borsa İstanbul Uygulaması (Omega Ratıo For Measurıng The Security Performance: An Applıcatıon On Borsa Istanbul). Uluslararası 23. Finans Sempozyumu Bildiri Kitabı. Aralık, 2019. İstanbul: Marmara Üniversitesi Yayınevi, 494-511.

Uyar, U. ve Gökçe, A. (2015). 2008 Küresel Ekonomik Krizinin Bankacılık Hisse Senetleri Performansı Üzerine Etkisi. Finansal Araştırmalar Ve Çalışmalar Dergisi. 7(12) , 209225.

Uyguntürk, H. ve Bal K. (2020). Emeklilik ve Menkul Kıymet Yatırım Fonlarının Gri İlișkisel Analiz Yöntemi ile Karşılaştırmalı Performans Analizi. Bartın Üniversitesi Íktisadi ve Ídari Bilimler Fakültesi Dergisi. 11(21), 298-320.

Verma M. ve Hirpara J.M. (2016). Performance Evaluation of Portfolio Using the Sharpe, Jensen, and Treynor Methods. Scholars Journal of Economics, and Management. 3(7), 382-390.

\section{INTERNET KAYNAKLARI}

www.spk.gov.tr, (Erişim: 06.02.2021)

www.tefas.gov.tr, (Erişim: 06.02.2021) 
EK: Çalışmada Verileri Kullanılan Hisse Senedi Yatırım Fonları ve Kodları

\begin{tabular}{|c|c|}
\hline Kod & Hisse Senedi Yatırım Fonları \\
\hline AAV & ATA PORTFÖY İKINCİ HISSE SENEDİ FONU (HIISSE SENEDİ YOĞUN FON) \\
\hline ACK & İSTANBUL PORTFÖY HİSSE SENEDİ FONU(HİSSE SENEDİ YOĞUN FON) \\
\hline ADP & AK PORTFÖY BISTT BANKA ENDEKSİ HİSSE SENEDİ FONU (HISSSE SENEDİ YOĞUN FON) \\
\hline$\overline{\mathrm{AFA}}$ & AK PORTFÖY AMERIKA YABANCI HİSSE SENEDİ FONU \\
\hline AFS & AK PORTFÖY GELIȘEN ÜLKELER YABANCI HİSSE SENEDİ FONU \\
\hline AFT & AK PORTFÖY YENİ TEKNOLOJILLER YABANCI HISSE SENEDİ FONU \\
\hline $\mathrm{AFV}$ & AK PORTFÖY AVRUPA YABANCI HISSE SENEDI FONU \\
\hline AHI & ATLAS PORTFÖY BİRINCİ HİSSE SENEDİ FONU(HİSSE SENEDİ YOĞUN) \\
\hline AKU & AK PORTFÖY BIST 30 ENDEKSİ HİSSE SENEDİ FONU (HİSSE SENEDİ YOĞUN FON) \\
\hline AK3 & AK PORTFÖY HISSS SENEDİ FONU (HISSE SENEDİ YOĞUN FON) \\
\hline ALC & AK PORTFÖY BIST TEMETTÜ 25 ENDEKSİ HISSSE SENEDİ FONU (HISSE SENEDİ YOĞUN FON) \\
\hline AOY & AK PORTFÖY YABANCI HISSE SENEDİ FONU \\
\hline$\overline{\text { AYA }}$ & ATA PORTFÖY BİRİNCİ HİSSE SENEDİ FONU (HİSSE SENEDİ YOĞUN FON) \\
\hline DAH & DENIZZ PORTFÖY HISSE SENEDI FONU (HISSSE SENEDİ YOĞUN FON) \\
\hline DZE & DENIZ PORTFÖY BIST 100 ENDEKSİ HIISSE SENEDİ FONU(HİSSE SENEDİ YOĞUN FON) \\
\hline EC2 & GLOBAL MD PORTFÖY BİRİNCİ HISSE SENEDİ FONU(HİSSE SENEDİ YOĞUN FON) \\
\hline EID & QIINVEST PORTFÖY HİSSE SENEDİ FONU (HİSSE YOĞUN FON) \\
\hline FYD & QNB FINANS PORTFÖY BIRINCI HISSE SENEDI FONU (HISSE SENEDI YOĞUN FON) \\
\hline GAE & GARANTİ PORTFÖY BİST30 ENDEKSİ HİSSE SENEDİ FONU (HISSE SENEDİ YOĞUN FON) \\
\hline GAF & GEDİK PORTFÖY BİRİNCİ HİSSE SENEDİ FONU (HİSSE SENEDİ YOĞUN FON) \\
\hline GBG & GEDIK PORTFÖY G-20 ÜLKELERI YABANCI HİSSE SENEDİ FONU \\
\hline GHS & GARANTİ PORTFÖY HIISSE SENEDİ FONU (HISSSE SENEDİ YOĞUN FON) \\
\hline GL1 & AZIMUUT PYŞ BİRİNCİ HİSSE SENEDİ FONU (HİSSE SENEDİ YOĞUN FON) \\
\hline GMR & GEDIK PORTFÖY İKINCİ HİSSE SENEDİ FONU (HISSE SENEDİ YOĞUN FON) \\
\hline GSP & AZIMUT PYŞ KAR PAYI ÖDEYEN HISSE SENEDİ FONU (HISSE SENEDİ YOĞUN FON) \\
\hline HBU & HSBC PORTFÖY BİST 30 ENDEKSİ HİSSE SENEDİ FONU (HİSSE SENEDİ YOĞUN FON) \\
\hline HVS & HSBC PORTFÖY HİSSE SENEDİ FONU (HISSSE SENEDİ YOĞUN FON) \\
\hline ICF & ICBC TURKEY PORTFÖY HISSE SENEDİ FONU(HISSSE SENEDİ YOĞUN FON) \\
\hline KYA & KARE PORTFÖY HİSSE SENEDİ FONU(HİSSE SENEDİ YOĞUN FON) \\
\hline MAC & MARMARA CAPITAL PORTFÖY HİSSE SENEDİ FONU (HİSSE SENEDİ YOĞUN FON) \\
\hline ST1 & STRATEJI PORTFÖY BİRİNCİ HIISSE SENEDİ FONU(HİSSE SENEDİ YOĞUN FON) \\
\hline TAU & İŞ PORTFÖY BİST BANKA ENDEKSİ HİSSE SENEDİ FONU (HİSSE SENEDİ YOĞUN FON) \\
\hline TIE & İŞ PORTFÖY BIST 30 ENDEKSİ HISSSE SENEDİ FONU (HİSSE SENEDİ YOĞUN FON) \\
\hline TI2 & İŞ PORTFÖY HISSE SENEDİ FONU (HİSSE SENEDİ YOĞUN FON) \\
\hline TI3 & İŞ PORTFÖY İȘ BANKASI İŞTİRAKLERİ ENDEKSİ HİSSE SENEDİ FONU (HISSSE SENEDİ YOĞUN FON) \\
\hline TKF & TACIRLER PORTFÖY HISSE SENEDİ FONU (HISSE SENEDI YOĞUN FON) \\
\hline TLH & AURA PORTFÖY HİSSE SENEDİ FONU (HISSSE SENEDİ YOĞUN FON) \\
\hline TMG & İŞ PORTFÖY YABANCI HISSSE SENEDİ FONU \\
\hline TPR & İȘ PORTFÖY PY HISSE SENEDİ ÖZEL FONU (HİSSE SENEDI YOĞUN FON) \\
\hline TTE & $\begin{array}{l}\text { İŞ PORTFÖY BİST TEKNOLOJİ AĞIRLIKLI SINIRLAMALI ENDEKSİ HİSSE SENEDİ FONU (HİSSE SENEDİ } \\
\text { YOĞUN FON) }\end{array}$ \\
\hline TYH & TEB PORTFÖY HISSE SENEDİ FONU (HISSSE SENEDİ YOĞUN FON) \\
\hline TZD & ZİRAAT PORTFÖY HIISSE SENEDİ FONU (HİSSE SENEDİ YOĞUN FON) \\
\hline YAS & YAPI KREDİ PORTFÖY KOÇ HOLDİNG İSTIİRAK VE HİSSE SENEDİ FONU(HİSSE SENEDİ YOĞUN FON) \\
\hline YAY & YAPI KREDI PORTFÖY YABANCI TEKNOLOJI SEKTÖRÜ HİSSE SENEDİ FONU \\
\hline YDI & YAPI KREDİ PORTFÖY İKINCİ HISSSE SENEDİ FONU (HISSE SENEDİ YOĞUN FON) \\
\hline YEF & YAPI KREDİ PORTFÖY BIST 30 ENDEKSI HISSSE SENEDİ FONU (HİSSE SENEDİ YOĞUN FON) \\
\hline YHS & YAPI KREDİ PORTFÖY BİRİNCI HİSSE SENEDİ FONU (HIISSE SENEDİ YOĞUN FON) \\
\hline ZPE & ZIRAAT PORTFÖY KATILIM ENDEKSI HISSE SENEDİ FONU (HISSE SENEDİ YOĞUN FON) \\
\hline
\end{tabular}


ETÜ Sentez İktisadi ve İdari Bilimler Dergisi

ETU Synthesis Journal of Economic and Administrative Sciences

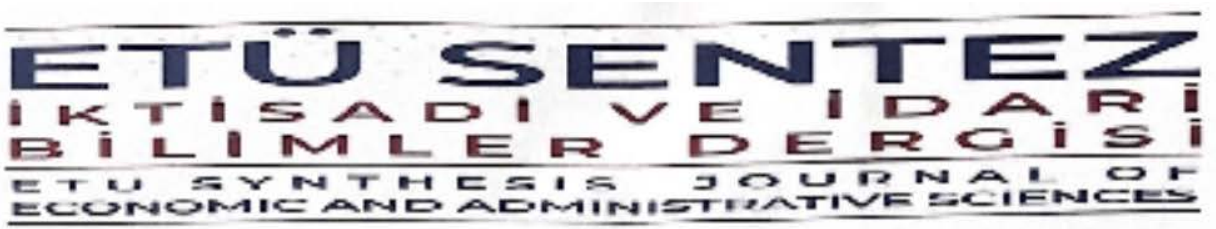

ETÜ Sentez İtisadi ve Idari Balimler Deryisi

ETU Synihasis Jeornai of Eownowic and Adwinistratrue Sefercer

Araştırmactlarn Katkı Oranı Beyanı ve Cutşama Beyanı

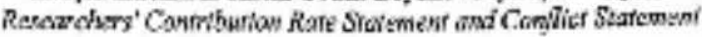

\begin{tabular}{|c|c|c|c|c|c|c|}
\hline \multicolumn{3}{|c|}{ 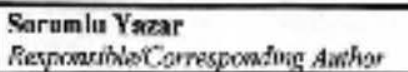 } & \multicolumn{4}{|c|}{ Zehra Tamyedi AKSOY } \\
\hline \multicolumn{3}{|c|}{$\begin{array}{l}\text { Mukaleuin Buslges } \\
\text { Title of Maraucrija }\end{array}$} & \multicolumn{4}{|c|}{$\begin{array}{l}\text { HISSF SFNFD SFMSTYE FUNLARTNN COMEGA PERFORMANS } \\
\text { ANAI.IT. }\end{array}$} \\
\hline \multicolumn{3}{|c|}{$\begin{array}{l}\text { Tarlb } \\
\text { Date }\end{array}$} & \multicolumn{4}{|c|}{22.032021} \\
\hline \multicolumn{4}{|c|}{$\begin{array}{l}\text { Makalenin törü (Arayturma makalesi, Derieme vh.) } \\
\text { Mamuseript Type (Resescel Article, Review etc.) }\end{array}$} & \multicolumn{3}{|l|}{ Arag̣tanas Mskalesi } \\
\hline \multicolumn{7}{|c|}{ 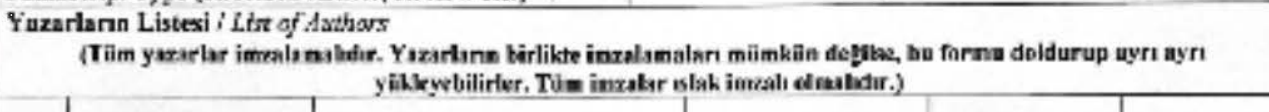 } \\
\hline $\begin{array}{l}\text { Sirg } \\
\text { No }\end{array}$ & $\begin{array}{l}\text { Adi-Soyadi } \\
\text { Nawe - Suvnume }\end{array}$ & \multicolumn{2}{|c|}{$\begin{array}{l}\text { Kada Orant* } \\
\text { Anther Contributiens }\end{array}$} & Çıkar Çatışmasa** & Imza & $\begin{array}{l}\text { Turih } \\
\text { Date }\end{array}$ \\
\hline 1 & $\begin{array}{l}\text { Esing Tyen } \\
\text { Axsoy }\end{array}$ & \multirow{2}{*}{\multicolumn{2}{|c|}{ 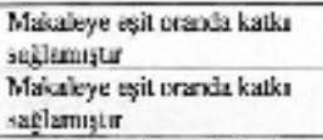 }} & $\begin{array}{l}\text { Cikar çalısmsi } \\
\text { b_lummamaktatir }\end{array}$ & & 22.03 .2021 \\
\hline 2 & Eevinichtia & & & $\begin{array}{l}\text { C.kar çatıșması } \\
\text { bulunmamaktari:r }\end{array}$ & 1.812 & 22.03 .2021 \\
\hline 3 & EEM COMLER & \multicolumn{2}{|c|}{$\begin{array}{l}\text { Makaleye esit cranda katis } \\
\text { saslamisctr }\end{array}$} & 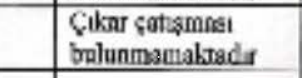 & & 22.05 .2001 \\
\hline \multicolumn{7}{|l|}{4} \\
\hline \multicolumn{7}{|c|}{\begin{tabular}{|l|l|l|l|l}
$s$ & & & & \\
\end{tabular}} \\
\hline \multicolumn{7}{|c|}{ 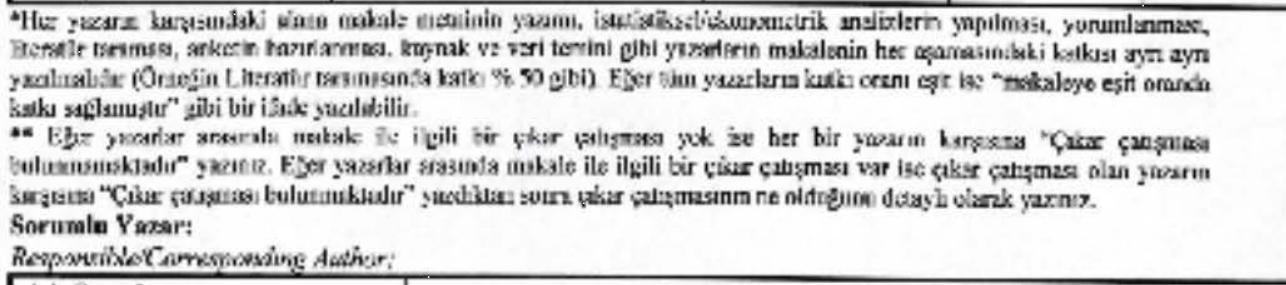 } \\
\hline \multicolumn{3}{|c|}{$\begin{array}{l}\text { Adr-Suyadt } \\
\text { Neme-Stumane }\end{array}$} & \multicolumn{4}{|c|}{ Zehra Tanyeli AKSOY } \\
\hline \multicolumn{3}{|c|}{ 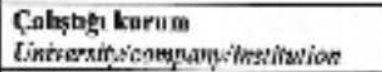 } & \multicolumn{4}{|c|}{ Dǚx Ünirersitesißsosyal Bilimler Enstitusa } \\
\hline \multicolumn{3}{|c|}{ Posta adresi dddress } & \multicolumn{4}{|c|}{ Tgégelar wh. Celin sh. Nu.:10 Kr::2 } \\
\hline \multicolumn{3}{|c|}{ E-pusta E-mat? } & \multicolumn{4}{|c|}{ zehratamyelingigmail.cow } \\
\hline \multicolumn{3}{|c|}{ Telefon Numurus Phans } & \multicolumn{4}{|c|}{05414266633} \\
\hline
\end{tabular}

Sorumle Yarar;

Respoverïhe Carresponabg Awthor

Zehrn 'Tanyeli $\Lambda \mathrm{KSOY}$

\begin{tabular}{|c|c|}
\hline Imza ipignalure & Turih / Dats \\
\hline d... & $\ldots 22 \ldots \ldots . \ldots 3 \ldots \ldots \ldots$ \\
\hline
\end{tabular}

